\title{
Heat Pump Bridge Analysis Using the Modified Energy Transfer Diagram
}

\author{
Florian Schlosser ${ }^{1, *}$, Heinrich Wiebe ${ }^{1}$, Timothy G. Walmsley ${ }^{2}$, Martin J. Atkins ${ }^{2}$, Michael R. W. Walmsley ${ }^{2}$ \\ and Jens Hesselbach ${ }^{1}$ \\ 1 Department Sustainable Products and Processes, University of Kassel, Kurt-Wolters-Straße 3, \\ 34125 Kassel, Germany; uk015044@student.uni-kassel.de (H.W.); hesselbach@upp-kassel.de (J.H.) \\ 2 Energy Systems Integration Group, School of Engineering, University of Waikato, \\ Hamilton 3216, New Zealand; tim.walmsley@waikato.ac.nz (T.G.W.); martin.atkins@waikato.ac.nz (M.J.A.); \\ walmsley@waikato.ac.nz (M.R.W.W.) \\ * Correspondence: schlosser@upp-kassel.de; Tel.: +49-561-804-3442
}

Citation: Schlosser, F.; Wiebe, H.; Walmsley, T.G.; Atkins, M.J.; Walmsley, M.R.W.; Hesselbach, J. Heat Pump Bridge Analysis Using the Modified Energy Transfer Diagram. Energies 2021, 14, 137. https://doi.org/10.3390/en14010137

Received: 3 December 2020 Accepted: 24 December 2020 Published: 29 December 2020

Publisher's Note: MDPI stays neutral with regard to jurisdictional clai$\mathrm{ms}$ in published maps and institutional affiliations.

Copyright: (C) 2020 by the authors. Licensee MDPI, Basel, Switzerland. This article is an open access article distributed under the terms and conditions of the Creative Commons Attribution (CC BY) license (https:// creativecommons.org/licenses/by/ $4.0 /)$.

\begin{abstract}
Heat pumps are the key technology to decarbonise thermal processes by upgrading industrial surplus heat using renewable electricity. Existing insight-based integration methods refer to the idealised Grand Composite Curve requiring the full exploitation of heat recovery potential but leave the question of how to deal with technical or economic limitations unanswered. In this work, a novel Heat Pump Bridge Analysis (HPBA) is introduced for practically targeting technical and economic heat pump potential by applying Coefficient of Performance curves into the Modified Energy Transfer Diagram (METD). Removing cross-Pinch violations and operating heat exchangers at minimum approach temperatures by combined application of Bridge Analysis increases the heat recovery rate and reduce the temperature lift to be pumped at the same time. The insight-based METD allows the individual matching of heat surpluses and deficits of individual streams with the capabilities and performance of different market-available heat pump concepts. For an illustrative example, the presented modifications based on HPBA increase the economically viable share of the technical heat pump potential from $61 \%$ to $79 \%$.
\end{abstract}

Keywords: heat pump integration; Pinch Analysis; retrofit; Modified Energy Transfer Diagram

\section{Introduction}

Pinch Analysis (PA) enables an engineer to target and develop heat integration solutions. The graphic tools of this method intuitively visualises the best paths to integrate a heat pump (HP) into an industrial process [1]. In PA, all thermal process streams are separated into heat surpluses and deficits and superimposed graphically according to temperature and heat capacity flow rate in the form of cold and hot Composite Curves (CC). As a step further, the Grand Composite Curve (GCC) is built by plotting the net heat deficits and surpluses for every temperature level. The resulting Pinch temperature is the characteristic temperature that divides the thermodynamic system into an area with cooling demand (below the Pinch) and an area with heating demand (above the Pinch). The correct integration of a HP is across the Pinch by recovering surplus heat from below the Pinch and upgrading heat for streams with heat deficits above the Pinch. Non-compliance with this principle leads to either an ineffective HP upgrading heat from above the Pinch (which can already fulfill a heating purpose), or additional waste heat being generated below the Pinch. The amount of additional waste heat is equal to the work provided to the HP. Figure 1 compares (a) the principle of the conventional separate supply of heating energy by a fossil-fired boiler and cooling energy by a chiller, and (b) a HP providing both for an exemplary GCC. The lighter green areas are excluded in the analysis of energy supply systems because they represent already exploited heat recovery pockets. 



Figure 1. Grand Composite Curves illustrating the integration of (a) a separate supply system by conventional fossil-fired boiler and chiller compared to (b) a cogeneration of heating and cooling by a HP (own illustration adapted from [2], shown in [3]).

After identifying the potential for increasing energy efficiency of a process through conventional heat recovery, HPs can meet a portion or all of the remaining cooling and heating demands simultaneously [4]. HPs, driven by renewable electricity, can efficiently extract ambient heat or recover waste heat for industrial low-temperature heating purposes [5]. In addition to environmental heat such as air, water or ground heat with temperatures up to about $30^{\circ} \mathrm{C}$, industrial waste heat such as sewage, cooling water and process waste (and excess) heat offer heat sources up to about $100^{\circ} \mathrm{C}$ [6]. Market-available HPs achieve up to $165^{\circ} \mathrm{C}$ supply temperatures [7]. The duel benefit of avoiding heating and cooling costs by operating industrial HPs emphasizes its special economic relevance [8], while also reducing greenhouse gas emissions (GHGE). In addition to high electricity-gas price ratios in combination with unfavourable profitability requirements, the missing awareness of meaningful application possibilities among stakeholders and a lack of an insight-based integration method that also considers practical restrictions hinder further market penetration.

\subsection{State-of-the-Art}

This section summarises the most recent state of research in the two fields of HP integration and retrofit and highlights the research gap for a systematic improvement of heat integration through a combined application of heat recovery and HPs.

\subsubsection{Heat Pump Integration Methods}

As illustrated in Figure 1, industrial HPs only use surplus waste heat efficiently when reduced from below the Pinch to meet remaining heat demand above the Pinch. In 1983, Townsend and Linnhoff [9] firstly discussed the correct integration of HPs across the Pinch using the GCC. Thereafter, Wallin et al. [10] used the CC to identify the optimal type, size and temperature level of a HP. Schlosser et al. [3] reviewed the recent developments. In addition to the optimization approaches, the insight-based approaches in particular support engineers in identifying a suitable integration point.

In their work, Stampfli et al. [11] combined the advantages of insight-based and automated approaches. They used COP curves [12] and supply and demand curves [13] on the one hand to find an optimal solution with a fast processing time, and on the other hand to visualise intuitively the integration. Schlosser et al. [14] summarised case studies in the dairy, galvanic, meat, sterilisation, machine and paper industries using this approach. Van de Bor and Ferreira [15] pointed out that the commonly used constant ratio of Carnot comparison to irreversible process, expressed by the Second Law efficiency $\eta_{2 n d}$, may underestimate the advantages of certain HPs, such as the sensible heat release of a transcritical $\mathrm{HP}$ in a gas cooler. Fu and Gundersen [16] suggested a novel HP design approach on the basis of the reversed Brayton cycle for better mapping the temperature change on process side than the frequently used reversed Rankine cycle assuming an isothermal heat transfer. Oluleye et al. [17] developed the primary fuel recovery ratio as a HP technology selection criterion using simplified correlation between ideal and real efficiency. The Exergy Per total annual Cost criterion (EPC) was proposed by Wang et al. [18] to select HPs based on their 
economic and thermodynamic performance. Gai et al. [19] emphasised the importance of matching the correct HP type with the thermal requirement of each process. While, for example, transcritical HPs are better suited for sinks with large temperature changes and sources with small, vapour compression HPs are better suited for near-constant constant sink and source temperatures. Recently, Yang et al. [20] brought together simulation-based targeting and PA for integration of HPs in heat exchanger networks (HEN). They found that for their particular case study that by including the properties of the working fluid into the simulation utility costs could be minimised further.

All these approaches have in common that they are based on the ideal framework of PA methods. Existing plants, however, rarely meet the minimum Pinch targets illustrated by the GCC. The formation of the GCC presupposes a complete exploitation of the heat recovery potential, which cannot be achieved due to practical process restrictions, such as temporal and spatial distances and process and safety-related aspects. Often removing heat exchangers (HEXs) and redesigning the HEN from scratch is too expensive or the installed HEX is unchangeable due to process engineering reasons. For these reasons it is important to identify the existing Pinch violations and remove them in the best possible way. However, the GCC just represents the ideally remaining heating and cooling demand neglecting the actual HEN design. For this reason, the additional demand exceeding the MET is not taken into account in the so far existing HP targeting methods. The weakness of this idealised approach is that the remaining heating and cooling demands of a real HEN design are not taken into account for the placement of HPs. This results in errors regarding dimensioning, potential and integration point. An approach to consider process restrictions or retrofit options for HP integration is currently missing in the scientific literature.

\subsubsection{Retrofit Approaches}

While conventional PA based tools provide insights and idealised target values according to which economic HEN and utilities are to be planned, they have limitations in retrofit situations for improving the efficiency of a HEN. Heat retrofits attempt to resolve Pinch violations in the HEN, primarily through removing cross-Pinch heat transfer [21]. Many existing plants, however, have substantial cross-Pinch heat transfer but struggle to identify a series of cost-effective retrofits [22]. Many modifications are often required to remove all the cross-Pinch heat transfer and so significant energy reductions are difficult to realise in practice. A sound and reliable integration of HPs requires further development of such tools. The challenge of developing new PA-based instruments considering the current HEN and process restrictions for possible retrofits has been examined in several papers.

Nordman and Berntsson [23] used Advanced Composite Curves (ACC) to identify and correct cross-Pinch violations. Cross-Pinch violations mean incorrect integration of HEXs that transfer heat across the Pinch and thus violate the Pinch rules. ACC represent all HEXs of a HEN in the form of connecting lines between the CC. Ideally, vertical heat transfer occurs between streams on the CC. In practice, in addition to cross-Pinch violation, nonvertical heat transfer occurs, meaning two heat exchangers whose T-Ḧ-plot runs crosswise. Although the presented approaches aim at resolving the violations and show possibilities for improved rearrangement of heat exchangers or substitution by utilities, HPs are not considered in this context.

Lai et al. [24] also aimed to identify cross-Pinch violations. They use the individual Stream Temperature versus Enthalpy Plot (STEP) of each individual stream, which facilitates the subsequent linking of streams in the overlapping T-H-region above or below the Pinch. The method is suitable for both greenfield planning and retrofitting. Due to the individual representation of each stream, the diagram becomes unclear for a higher number of streams. A targeted exploitation of the heat recovery potential is not possible due to the lack of target values.

While the two previous approaches were based on the CC, Kamel et al. [25] visualised the Temperature Driving Force (TDF) within a HEN over the absolute temperature in a diagram. Compared to the previous approaches, the TDF allows a deeper insight into 
the efficiency of already integrated HEX. The heat recovery potential can be increased by minimising the TDF within the HEX. However, the visualisation form is not very accessible compared to the conventional graphic PA tools.

The Shifted Retrofit Thermodynamic Grid Diagram (SRTGD) of Yong et al. [26] showed heat capacity flow rate $(C P)$ over shifted temperatures $\left(T^{*}\right)$ within an HEN and enable the screening of favourable heat paths. It discusses different topologies and thus enables the consideration of changing energy carrier prices to identify an economic retrofit solution.

Bonhiver et al. [27] introduced the concept of Bridge Analysis (BA) and developed the Energy Transfer Diagram (ETD) for graphical illustration. Similar to the conventional paths and loops based retrofit methods [28], BA aims to find energy saving pathways between hot and cold utility. The ETD supports the identification of heat transfer bridges within a HEN and explains how heat is transferred from a heater along heat recovery HEX via the cooler to the environment $[29,30]$. For this purpose, the ETD is constructed from Exchanger Grand Composite Curves (EGCC) representing the individual GCCs of each already integrated HEX (utility and recovery HEX) of the HEN. Subsequently, the EGCC are superimposed in the ETD. In contrast to the well-known tools of PA, Bonhiver et al. apply enthalpy flow rate $(\mathrm{H})$ on the $Y$-axis and the shifted temperature on the $X$-axis. The actual retrofit potential can be read from the difference of the $X$-axis and the lowest $\dot{H}$-value of the $Y$-axis. Furthermore, it is possible to identify unfavourably integrated HEXs in the form of cross-Pinch violations and high temperature driving forces. If the curve of an ETD covers a large area in the ETD, there is potential for optimization due to the large temperature driving force within the ETD. Small areas in the ETD imply correspondingly efficient HEXs with small temperature gradient, but this often requires large HEX areas. Despite its usefulness and validity, the ETD ignores the established visual communication tools of PA. In comparison to the GCC, the axes are reversed, and the characteristic colouring refers only to the utilities.

Since the GCC neither provides information on the individual streams of an existing HEN nor shows practical HP potential, it is of limited suitability for retrofitting and HP integration. Walmsley et al. [31] therefore modified the ETD to establish the connection between conventional PA tools and the ETD by superimposing the EGCC in the common $\mathrm{T}^{*}$-H-diagram and using the known colouring of hot streams in red and cold streams in blue. The new Modified Energy Transfer Diagram (METD) was constructed by stacking each individual EGCC at each temperature interval in the order of heaters, coolers and recovery HEXs. It allows the graphical determination of retrofit options (heat transfer bridges) and their heat recovery potentials. An important progress in this work is the presentation and identification of segments with heat surplus or deficit in a HEN and the identification of the involved process streams in the METD. The right-hand profile of the METD mirrors the shape of the conventional GCC. The distance between the right-handed METD curve and the corresponding GCC represents the deviation between theoretical optimum and practical implementation and thus the retrofit potential. Lal et al. [32] proposed the Heat Surplus and Deficit Table (HSDT) as the numerical counterpart of the METD which enables algorithmically identifying and quantifying of retrofit bridges. It is derived by balancing heat deficit and surplus within the shifted temperature intervals of each HEX in the HEN. Walmsley automated the BA [33] to find the cost-optimal retrofit design under consideration of constraints using the branch-and-bound approach.

Retrofitting HPs into the HEN, while also making other conventional modifications, offers an alternate and potentially practical approach to achieve large hot and cold utility reductions. It is important in practice to pinpoint which streams exchange heat with the HP's evaporator and condenser and how such heat pumping leads to utility reduction.

\subsection{Objective}

This paper aims to extend the METD method to include the integration of HPs into the retrofit of HEN for systematically improving energy efficiency. The novelty is the targeting of HPs by Coefficient of Performance (COP) curves using the METD instead of the GCC, which enables heat sources that have not been utilised for HR to be considered 
for upgrading via a HP. Furthermore, the approach developed allows the matching of the capabilities of market-available HP types in terms of real performance and application limits with the process requirements visualised by the METD.

In this work, Section 2 initially provides an overview of the energetic and economic efficiency and technical limitations of market-available HPs. Subsequently, the novel HPBA is introduced step by step in Section 3 and its advantages and validity is illustrated by the case study presented. To ensure efficient HP integration, BA is applied to increase heat recovery rate by removing cross-Pinch violations and minimise temperature lift by operating HEX at minimum approach. Suitable HPs are placed on different integration levels (utility or process level) to overcome unfeasible heat cascade between heat surplus and deficit. This approach opens up previously unconsidered implementation potentials, especially for retrofitting, and avoids oversizing of both HEX and HP. Finally, results of the modification levels are compared and discussed.

\section{Review of Market-Available Industrial Heat Pump Performance and Economic Feasibility}

This section reviews regression models of real-world performance data of marketavailable large-scale HP technologies $\left(\dot{\mathrm{Q}}_{\mathrm{Cond}, \mathrm{HP}}>50 \mathrm{~kW}_{\mathrm{th}}\right)$. Standard compression heat pumps (SHP) achieve heat supply temperatures of up to $100^{\circ} \mathrm{C}$. Very-high-temperature heat pumps (VHTHP) reach supply temperatures of up to $165^{\circ} \mathrm{C}$ [7]. The performance of a HP is often modelled by the Equation (1) estimating the real COP through the CarnotCOP and a constant 2nd Law efficiency. According to EN 14511-2 [34], the underlying temperature lift $\left(\Delta \mathrm{T}_{\text {lift }}\right)$ describes the difference between the heat source temperature entering the evaporator $\left(\mathrm{T}_{1, \text { in }}\right)$ and the heat sink temperature leaving the condenser $\left(\mathrm{T}_{\mathrm{h}, \mathrm{out}}\right)$.

$$
\mathrm{COP}=\eta_{2 \text { nd }} \cdot \mathrm{T}_{\mathrm{h}, \text { out }} /\left(\mathrm{T}_{\mathrm{h}, \text { out }}-\mathrm{T}_{1, \text { in }}\right)=\eta_{2 \text { nd }} \cdot \mathrm{T}_{\mathrm{h}, \text { out }} / \Delta \mathrm{T}_{\text {lift }}
$$

A major disadvantage of this approach is that constant values for 2nd Law efficiency are only suitable for mid-range $\Delta \mathrm{T}_{\text {lift }}$ values. The analysis of the HP database from Jesper et al. [35] reveals that $\eta_{2 \text { nd }}$ substantially decreases towards the lower and upper end of the $\Delta \mathrm{T}_{\text {lift }}$ range. The newly developed models [35] using the following Equation (2) and the fitting parameter $\mathrm{a}, \mathrm{b}, \mathrm{c}$ and $\mathrm{d}$ in Table A2, model this behaviour over a wide range of temperature lifts with significantly increased accuracy.

$$
\begin{aligned}
& C O P=a \cdot\left(\Delta \mathrm{T}_{\text {lift }}+2 \cdot b\right)^{\mathrm{c}} \cdot\left(\mathrm{T}_{\mathrm{h}, \text { out }}+\mathrm{b}\right)^{\mathrm{d}} \\
& \mathrm{COP}=\mathrm{a} \cdot\left(\Delta \mathrm{T}_{\text {lift, }}+2 \cdot \mathrm{b}\right)^{\mathrm{c}} \cdot\left(\mathrm{T}_{\mathrm{h}, \mathrm{m}}+\mathrm{b}\right)^{\mathrm{d}}
\end{aligned}
$$

The fitting parameters $a, b, c$ and d (cf. Table A2 in Appendix A) specify the efficiency of SHP using hydrofluorocarbons (HFC) and hydrofluoroolefins (HFO), water/water or water/steam VHTHP using hydrochlorofluoroolefins (HCFO), HFC and HFO, SHP using R717 as well as transcritical $\mathrm{CO}_{2}-\mathrm{HPs}$ based on Equation (3). The latter accounts the transcritical heat release in the gas cooler by the Lorentz comparison process and uses the mean sink temperature $\left(\mathrm{T}_{\mathrm{h}, \mathrm{m}}\right)$ as well as the mean temperature lift $\left(\Delta \mathrm{T}_{\text {lift,m }}\right)$.

For SHPs, the standard deviation $(\sigma)$ is reduced from 0.80 to 0.28 and the coefficient of determination $\left(\mathrm{R}^{2}\right)$ is increased from 0.78 to 0.96 . In addition, Jesper et al. [35] found that the operating temperatures have the greatest influence on the efficiency of the analysed HPs. In contrast, no effects on efficiency were observed for the compressor type, the refrigerant and other differences in system design.

A high accuracy of the COP estimation is a prerequisite for both the correct technical integration and a reliable feasibility assessment of HP applications regarding their economic and environmental impact compared to conventional heat supplier like fossil-fired standard gas boilers (SGB). A nomogram compares the levelized cost of heat ( $\mathrm{LCOH})$ of SHP and SGB depending on different cost ratio of electricity and natural gas $\mathrm{c}_{\mathrm{el}} / \mathrm{c}_{\mathrm{ng}}$ and temperature lifts $\left(\Delta \mathrm{T}_{\text {lift }}\right)$ according to the annuity method described by Schlosser [3]. Figure 2 presents 
the cost parity curve $\left(\mathrm{LCOH}_{\mathrm{HP}} / \mathrm{LCOH}_{\mathrm{SGB}}=1\right)$ of market-available HPs. The cost parity describes the critical value (break-even) in terms of economic feasibility. Values below the parity curve of the individual HP mean economically implementations. The underlying $\mathrm{COP}_{\mathrm{i}}$ are based on the model parameters presented in Table A2 (cf. Appendix A). The parameters of the nomograms are summarized in Table A1.

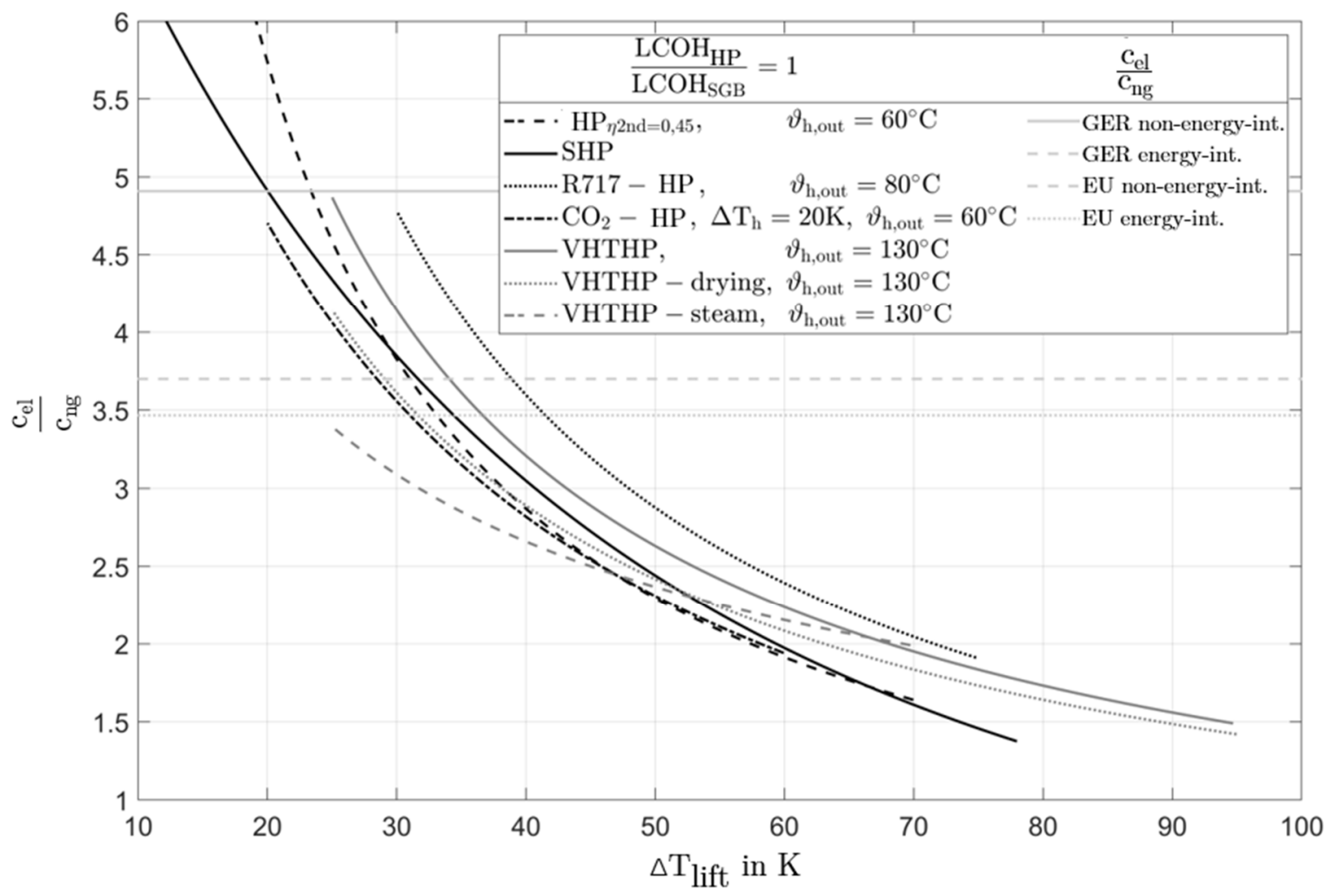

Figure 2. Break-even $\left(\mathrm{LCOH}_{\mathrm{HP}} / \mathrm{LCOH}_{\mathrm{SGB}}=1\right)$ for different $\Delta \mathrm{T}_{\text {lift }}$ and $\mathrm{c}_{\mathrm{el}} / \mathrm{c}_{\text {ng }}$ and market-available HPs (adapted from [3]).

A typical price ratio $c_{\mathrm{el}} / \mathrm{c}_{\mathrm{ng}}$ for energy-intensive companies consuming electricity between 70 and $150 \mathrm{GWh}$ and natural gas between 280 and $1100 \mathrm{GWh}$ in Europe is 3.5 [36]. Energy-intensive European companies $\left(c_{\mathrm{el}} / \mathrm{c}_{\mathrm{ng}}=3.5\right)$ achieve economic implementations in the range of $37 \mathrm{~K}<\Delta \mathrm{T}_{\text {lift,break-even }}<42 \mathrm{~K}$ in the ascending order: steam-generating $\mathrm{HP}$ (VHTHP-steam), transcritical $\mathrm{CO}_{2}$-HP, drying HP (VHTHP-drying), HP based on a constant Second Law efficiency $\eta_{2 n d}$, SHP up to $100{ }^{\circ} \mathrm{C}$, high-temperature HP up to $160{ }^{\circ} \mathrm{C}$ (VHTHP) and ammonia HP (R717-HP). The R717 HP has the greatest economic advantage, but only applies in a small sink temperature interval $\left(70{ }^{\circ} \mathrm{C} \leq \mathrm{T}_{\mathrm{h} \text {,out }} \leq 85^{\circ} \mathrm{C}\right)$. At sink temperatures of $\mathrm{T}_{\mathrm{h} \text {,out }}>85^{\circ} \mathrm{C}$, the water-based VHTHP is most beneficial. In the low-temperature range $\left(\mathrm{T}_{\mathrm{h}, \text { out }}<70^{\circ} \mathrm{C}\right)$, the temperature change between inlet and target temperature of the heat sink determines the favourability between $\mathrm{SHP}$ and $\mathrm{CO}_{2}-\mathrm{HP}$. A cost parity curve based on the commonly used Carnot COP assuming a constant Second Law efficiency of $\eta_{2 n d}=0.45$ is also displayed to show the possible error regarding the economic feasibility. On average, an economically critical temperature lift of $\Delta \mathrm{T}_{\text {lift,break-even }}=38 \mathrm{~K}$ is used as the target value in this work. Nevertheless, it is possible to select a specific HP and price ratio for a certain case study.

\section{Method: Heat Pump Bridge Analysis}

In this section, the necessary retrofit tools and their application for a HEN optimization and practical HP integration are shown. The aim of the retrofit is to maximise the heat recovery potential relative to some financial criteria by modifying the HEN by systematically adding more HEX or HP. An extended approach is derived from the BA, which enables both targeting retrofit and HP options for a HEN using the Heat Pump Bridge Analysis 
(HPBA) and the METD. Figure 3 shows the general approach of the HPBA extending the approach of Lal [32] by the steps (0 and 5-9) highlighted in green. They are crucial for modifying HEN step by step enabling an energetically efficient integration of the HP.

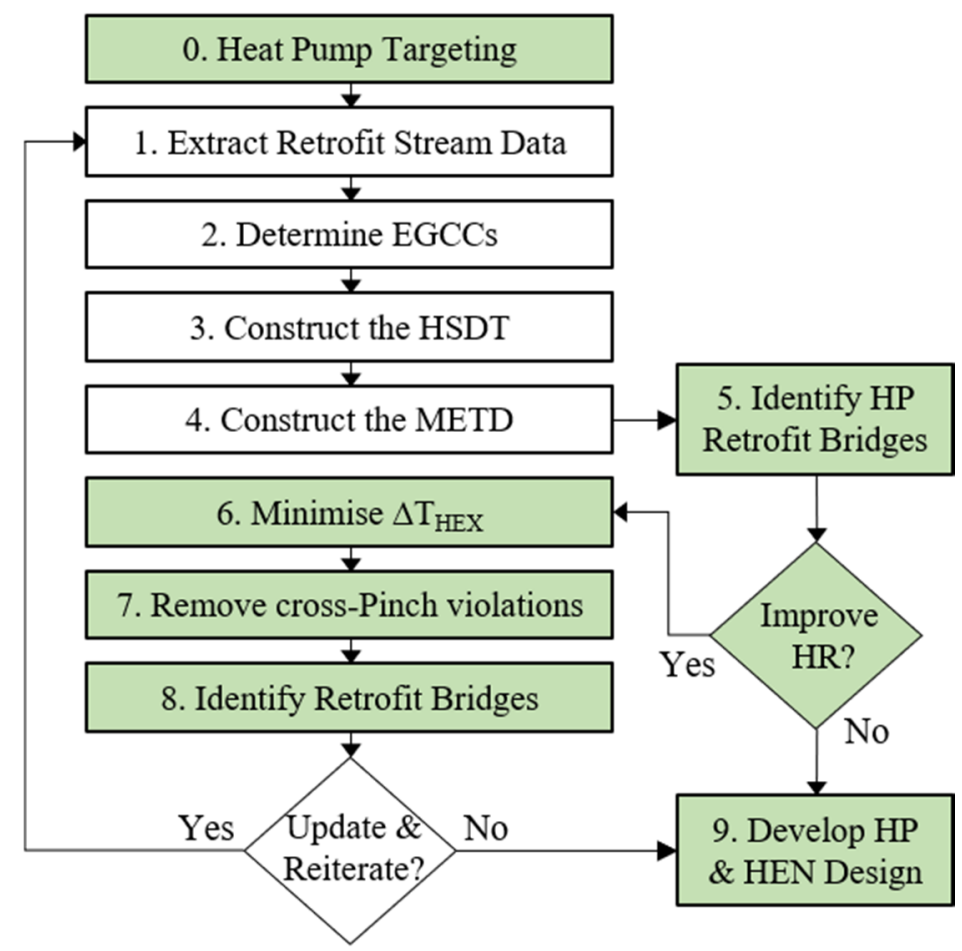

Figure 3. HPBA: Novel hybrid HEN and HP retrofit targeting method (white: existing steps of Lal et al. [32]; green: new steps of HPBA).

At the beginning (step 0), a benchmark should be set, analogous to the conventional PA procedure, to provide design targets. In contrast to the existing approaches, the technoeconomic potential is directly identified for this purpose via the limiting temperature lifts. After the well-known steps (1 to 4 ) of the BA to construct HSDT and METD, the next step of the new HPBA is the analysis of HP bridge options (step 5) by applying the COP curve (cf. Section 3.1) into the METD. Afterwards there is the possibility to go directly into the development of a HP retrofitting HEN design (step 9) if no further improvement of heat recovery is needed or meaningful. Otherwise, a retrofit loop of the HEN (step 6-8) can be examined. The premise of these steps is an increase of the heat recovery rate and an increase in efficiency for integrating HPs. If a further iteration is desired, new HEN designs can be displayed again in the METD and examined for HP bridge options.

\subsection{Targeting of Techno-Economic Heat Pump Potential Using COP Curves}

Figure 4 presents the method for targeting HP-parameters for the given GCC. The approach used in this study is based on the method described by Schlosser et al. [14]. Deviating from this study, the COP curves are based on the regression results of Jesper et al. [35] and Schlosser et al. [3], summarized in Section 2 and Appendix A. In this way, integrations points can be target by matching the specific properties of the HP and their COP estimations with the requirements of the processes in terms of Pinch temperature and GCC shape. This method requires the specification of a target temperature and enthalpy flow on the source and sink sides of the GCC. Depending on the location of the target temperature and the shape of the GCC, a COP as a function of the temperature lift $\Delta \mathrm{T}_{\text {lift }}$ results. 


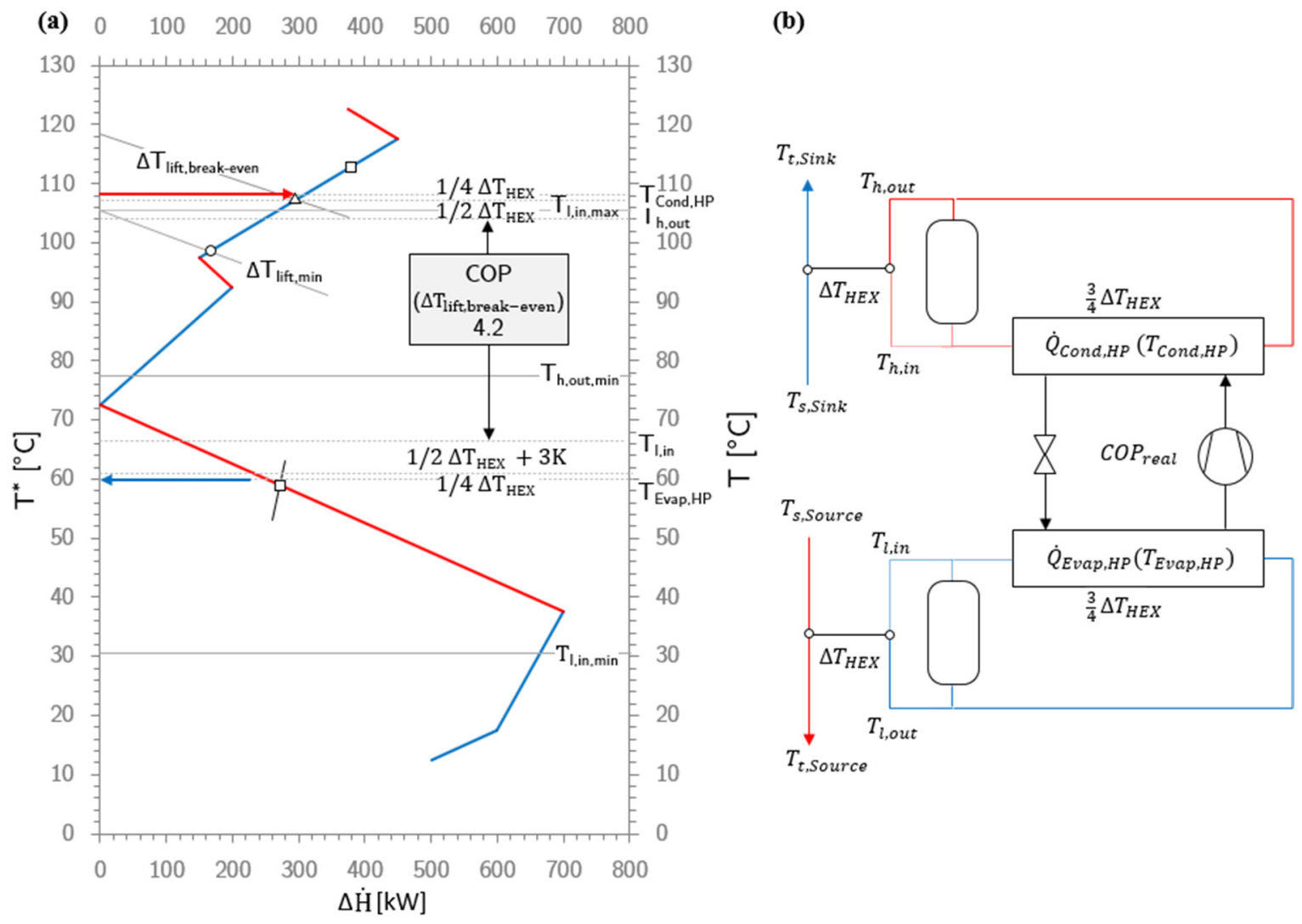

Figure 4. (a) Targeting technical (minimum: circle marker; maximum: square marker) and economical (triangle marker) HP potential by GCC and COP curves for a four-stream HEN [37] (b) Schematic illustration of the corresponding HP parameters according to [14].

Within the scope of the current work, it is now also possible to specify a target temperature lift $\left(\Delta \mathrm{T}_{\text {lift,target }}\right)$. Thus, technical (e.g., $\left.\Delta \mathrm{T}_{\text {lift,limit }}\right)$ and economical (e.g., $\left.\Delta \mathrm{T}_{\text {lift,break-even }}\right)$ temperature lifts can be considered. The technical potential of the respective HP is within the validity range shown in Table A2. Depending on the GCC, this can be determined by the upper or lower limit values of the temperature lift $\left(\Delta \mathrm{T}_{\text {lift,limit }}\right)$ or source temperature $\left(\mathrm{T}_{1, \text { in }}\right)$ and sink temperatures $\left(\mathrm{T}_{\mathrm{h}, \text { out }}\right)$. Otherwise, the availability of the heat sources and heat sinks, as indicated by the GCC, may also be limited. Using the GCC in this way will provide targets for parameters such as condenser and evaporator capacity and operating temperatures.

Figure 4 a displays the average net heat surplus and deficit of all source and sink streams at the corresponding temperature levels of the four-stream HEN. The economic temperature lift $\left(\Delta \mathrm{T}_{\text {lift,break-even }}\right)$ describes the critical limit value below which an investment is worthwhile. It can be read off at break-even with cost parity to a competing SGB depending on the company-specific electricity to gas price ratio $\left(\mathrm{c}_{\mathrm{el}} / \mathrm{c}_{\mathrm{ng}}\right)$ in Figure 2. The economic break-even temperature lift for a VHTHP is $\Delta \mathrm{T}_{\text {lift,break-even }}=38 \mathrm{~K}$ according to in Figure 2 for a price ratio of $\mathrm{c}_{\mathrm{el}} / \mathrm{c}_{\mathrm{ng}}=3.5$. The technical potential ranges between the process energy demand described by GCC/METD and the technological application limits of the respective HP technologies (cf. Table A2). Against this background, the following case distinctions define the limit values $\dot{\mathrm{Q}}_{\mathrm{H}, \mathrm{HP}, \min }$ (Equation (4)) and $\dot{\mathrm{Q}}_{\mathrm{H}, \mathrm{HP}, \max }$ (Equation (5)).

$$
\dot{Q}_{\mathrm{H}, \mathrm{HP}, \text { min }}=\left\{\begin{array}{cl}
\dot{\mathrm{Q}}_{\mathrm{H}, \mathrm{HP}}\left(\mathrm{COP}\left(\Delta \mathrm{T}_{\text {lift,min }}\right)\right) & \text { for } \mathrm{T}_{\mathrm{h}, \text { out }}\left(\Delta \mathrm{T}_{\text {lift,min }}\right)>\mathrm{T}_{\mathrm{h}, \text { out,min }} \\
\mathrm{Q}_{\mathrm{H}, \mathrm{HP}}\left(\mathrm{COP}\left(\Delta \mathrm{T}_{\text {lift,min }}\right)\right) & \text { for } \mathrm{T}_{\mathrm{h}, \text { out }}\left(\Delta \mathrm{T}_{\text {lift,min }}\right) \leq \mathrm{T}_{\mathrm{h}, \text { out,min }} \\
50 \mathrm{~kW} & \text { for }_{\mathrm{H}, \mathrm{HP}, \text { min }} \leq 50 \mathrm{~kW}
\end{array}\right.
$$




$$
\dot{\mathrm{Q}}_{\mathrm{H}, \mathrm{HP}, \text { min }}=\left\{\begin{array}{cc}
\dot{\mathrm{Q}}_{\mathrm{H}, \mathrm{HP}}\left(\mathrm{COP}\left(\Delta \mathrm{T}_{\text {lift,min }}\right)\right) & \text { for } \mathrm{T}_{\mathrm{h}, \text { out }}\left(\Delta \mathrm{T}_{\text {lift,min }}\right)>\mathrm{T}_{\mathrm{h}, \text { out,min }} \\
\mathrm{Q}_{\mathrm{H}, \mathrm{HP}}\left(\mathrm{COP}\left(\Delta \mathrm{T}_{\text {lift,min }}\right)\right) & \text { for } \mathrm{T}_{\mathrm{h}, \text { out }}\left(\Delta \mathrm{T}_{\text {lift,min }}\right) \leq \mathrm{T}_{\mathrm{h}, \text { out,min }} \\
\mathrm{Q}_{\text {Sink,tot }} & \text { for } \mathrm{Q}_{\mathrm{H}, \mathrm{HP}, \text { min }} \geq \mathrm{Q}_{\text {Sink,tot }} \\
\mathrm{Q}_{\mathrm{H}, \mathrm{HP}}\left(\mathrm{Q}_{\text {Source,tot }}\right) & \mathrm{Q}_{\mathrm{C}, \mathrm{HP}} \geq \mathrm{Q}_{\text {Source,tot }}
\end{array}\right.
$$

Reference values for the potential are the target temperature lift $\left(\Delta \mathrm{T}_{\text {lift,target }}\right)$ and the achievable coverage of the heating demand $\dot{\mathrm{Q}}_{\mathrm{H}, \mathrm{HP}}$ covered by the HP ( $\left.\dot{\mathrm{Q}}_{\mathrm{Cond}, \mathrm{HP}}\right)$.

$$
\dot{\mathrm{Q}}_{\mathrm{Cond}, \mathrm{HP}}\left(\mathrm{T}_{\mathrm{t}, \text { Sink }}^{*}\right)=\dot{\mathrm{Q}}_{\mathrm{H}, \mathrm{HP}}=\dot{\mathrm{Q}}_{\text {Evap }, \mathrm{HP}}\left(\mathrm{T}_{\mathrm{t}, \text { Source }}^{*}\right) \cdot\left(1-\frac{1}{\operatorname{COP}\left(\Delta \mathrm{T}_{\text {lift,target }}\right)}\right)^{-1}
$$

For this purpose, for each value of $\dot{\mathrm{Q}}_{\text {Source }}\left(=\dot{\mathrm{Q}}_{\mathrm{Evap}, \mathrm{HP}}\right)$ of the GCC/METD at its corresponding temperature level $\mathrm{T}_{\mathrm{t}, \mathrm{Source}}$ the Equation (6) in dependence of the target temperature lift $\left(\Delta \mathrm{T}_{\text {lift,target }}\right)$ is to be executed. Then, the resulting values of $\dot{\mathrm{Q}}_{\mathrm{Cond}, \mathrm{HP}}$ is to be plotted over their corresponding temperature levels $\mathrm{T}_{\mathrm{t}, \text { Sink }}\left(\Delta \mathrm{T}_{\text {lift,target }}\right)$ in the $\mathrm{T}-\Delta \dot{\mathrm{H}}-$ diagram of the GCC/METD. The intersection with the GCC identifies the corresponding condensing capacity $\left(\dot{\mathrm{Q}}_{\mathrm{Cond}, \mathrm{HP}}\right)$ and sink temperature $\left(\mathrm{T}_{\mathrm{t}, \mathrm{Sink}}\right)$. The relationship between process and refrigerant temperatures is described by Schlosser et al. [3] in detail. Figure $4 \mathrm{~b}$ illustrates the integration of a HP (including storage) using an intermediate fluid. The first part involves heat transfer between process streams and the intermediate fluid in a heat recovery loop (HRL) if necessary. A HRL is simply a closed-circuit coupled loop combing several heat sources below the Pinch and heat sinks above the Pinch. The second heat transfer is between the HP and HRL. To ensure a sufficient temperature driving force, an exchanger-specific temperature difference $\left(\Delta \mathrm{T}_{\mathrm{HEX}}\right)$ is selected. A value of $\Delta \mathrm{T}_{\mathrm{HEX}}=5 \mathrm{~K}$ is chosen, which is often a good trade-off between energy costs and the investment [38].

\subsection{Extraction of Retrofit Stream Data}

The HEN to be retrofitted consists of any number of process streams, cold utilities (coolers), hot utilities (heaters) and process-to-process HEXs. Like conventional BA, the following stream data are necessary for HPBA: supply (inlet) and target (outlet) temperatures for each stream interval in each HEX, specific heat capacity flow rate, existing HEX duties and the HEN structure. Either a global $\left(\Delta \mathrm{T}_{\text {min }}\right)$ or stream-specific $\left(\Delta \mathrm{T}_{\text {cont }}\right)$ minimum approach temperature is specified to define the retrofit targets and form the METD.

\subsection{Determine Exchanger Grand Composite Curves}

In this step, the EGCCs for each HEX are calculated individually using the Exchanger Problem Table Algorithm (E-PTA) [32]. Unlike conventional PA, where the standard PTA [39] superimposes a complete set of stream data without a defined heat recovery network to only one hot composite stream with a $\mathrm{CP}_{\mathrm{h}, \mathrm{i}}$ and one cold composite stream with a $\mathrm{CP}_{\mathrm{c}, \mathrm{i}}$ in each temperature interval $\mathrm{i}$, the E-PTA considers each HEX as a separate problem. The E-PTA is repeated for each individual HEX. The EGCC is built from the Shifted Composite Curve (SCC) according to Figure $5 \mathrm{a}, \mathrm{b}$ and represents the shifted temperatures $\mathrm{T}^{*}$, on the $Y$-axis and the heat cascade $\dot{\mathrm{H}}$ (Equation (10)) on the $X$-axis. E-PTA is a simplified case of the standard PTA, where for a balanced recovery HEX the first and last enthalpy value $\dot{H}$ must be zero (Figure 5c). 

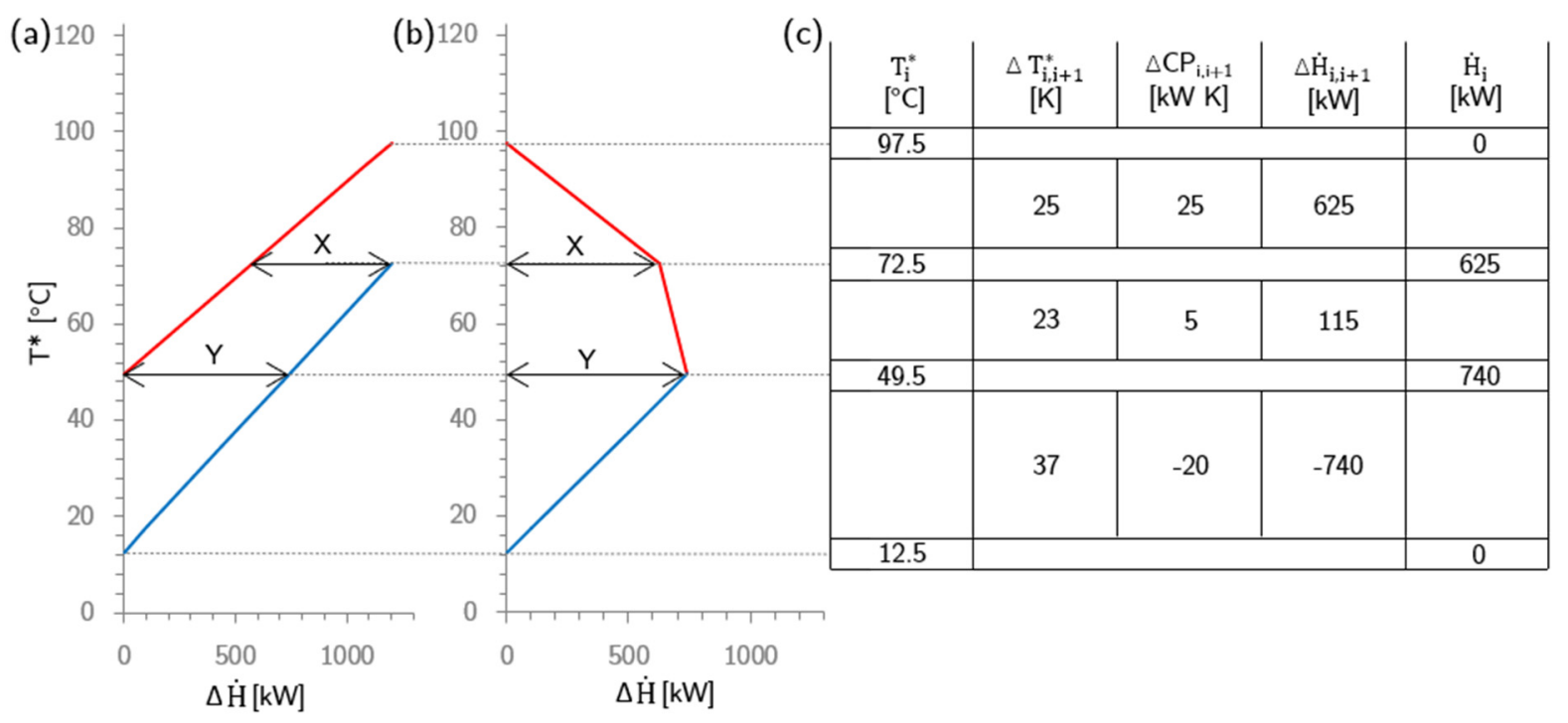

Figure 5. Development of the E-PTA (c) using SCC (a) und EGCC (b) of recovery exchanger E1 according to [31].

The $\Delta \dot{\mathrm{H}}_{\mathrm{i}, \mathrm{i}+1}$ is the net heat deficit or surplus within each temperature interval $[\mathrm{i}, \mathrm{i}+1]$, calculated by the temperature difference $\Delta \mathrm{T}_{\mathrm{i}, \mathrm{i}+1}$ and the net heat capacity flow rate $\Delta \mathrm{CP}_{\mathrm{i}, \mathrm{i}+1}$ according to Equations (7)-(9).

$$
\begin{gathered}
\Delta \mathrm{T}_{\mathrm{i}, \mathrm{i}+1}^{*}=\mathrm{T}_{\mathrm{i}}^{*}-\mathrm{T}_{\mathrm{i}+1}^{*} \\
\Delta \mathrm{CP}_{\mathrm{i}, \mathrm{i}+1}=\left(\mathrm{CP}_{\mathrm{h}}-\mathrm{CP}_{\mathrm{C}}\right)_{\mathrm{i}, \mathrm{i}+1} \\
\Delta \dot{\mathrm{H}}_{\mathrm{i}, \mathrm{i}+1}=(\Delta \mathrm{T} \cdot \Delta \mathrm{CP})_{\mathrm{i}, \mathrm{i}+1}
\end{gathered}
$$

The heat deficit or surplus values provide valuable information about the possibilities that heat can be re-integrated through retrofitting existing HEX matches to reduce external heat demand. The last column in Figure $5 c$ is the total heat cascade $\dot{H}_{i}$.

$$
\dot{\mathrm{H}}_{\mathrm{i}}=\dot{\mathrm{H}}_{\mathrm{i}-1}+\Delta \dot{\mathrm{H}}_{\mathrm{i}-1, \mathrm{i}}
$$

The initial value of the heat cascade is the total heat demand of the HEX $(\Delta \mathrm{H})$. For recovery HEX and cold utility exchangers, $\dot{\mathrm{H}}_{1}$ is zero, while for heaters $\dot{\mathrm{H}}_{1}$ represents the heating demand $\mathrm{HU}$. The last values $\dot{\mathrm{H}}_{\mathrm{n}}$. is zero for recovery HEX and represents the corresponding cooling demand $\mathrm{CU}$ for coolers.

\subsection{Construction of the Heat Surplus and Deficit Table}

After all process data have been identified in the first step, the heat surpluses and heat deficits of this HEN can be displayed in tabular form (HSDT) as the numerical counterpart of the METD. For this purpose, the net enthalpy flow rates $\Delta \dot{\mathrm{H}}_{\mathrm{i}, \mathrm{i}+1}$ for each temperature interval must be calculated according to Equation (9). The tabular visualisation of the HSDT enables the identification of retrofit bridge options. In the HSDT, positive $\Delta \dot{\mathrm{H}}_{\mathrm{i}, \mathrm{i}+1}$ values refer to heat surpluses while negative $\Delta \dot{\mathrm{H}}_{\mathrm{i}, \mathrm{i}+1}$ values refer to heat deficits. In contrast to the work of Lal [32] and Walmsley [31,33], in this version the Pinch temperature on the one hand and the possible shifting range of the individual streams on the other hand are highlighted in colour (cf. Figure 6). The red and blue horizontal lines show the hot and cold Pinch temperature, respectively, and facilitates the identification of cross-Pinch violations in order to derive appropriate modifications in the context of HPBA. The grey-shaded area is used to show the total temperature change of each process stream illustrating the possible shifting range as well as the existing heat cascade over the corresponding temperature intervals in the specific HEX between streams or stream and utilities. In addition, the stream integrated 
in the HEXs are considered separately in two columns. The intention is to facilitate the traceability of the process streams within the utilities.

\begin{tabular}{|c|c|c|c|c|c|c|c|c|c|c|c|c|c|c|c|}
\hline \multirow{3}{*}{$\mathbf{T}_{\mathbf{i}}$} & \multirow{2}{*}{$\mathbf{T}^{*}$} & \multicolumn{2}{|l|}{$\mathrm{C2}$} & \multicolumn{2}{|l|}{ C1 } & \multicolumn{4}{|c|}{ E1 } & \multicolumn{4}{|c|}{ E2 } & \multirow{2}{*}{\multicolumn{2}{|c|}{$\frac{\text { H1 }}{30 \mathrm{~kW} / \mathrm{K}}$}} \\
\hline & & \multicolumn{2}{|c|}{$25 \mathrm{~kW} / \mathrm{K}$} & \multicolumn{2}{|c|}{$15 \mathrm{~kW} / \mathrm{K}$} & \multicolumn{2}{|c|}{$25 \mathrm{~kW} / \mathrm{K}$} & \multicolumn{2}{|c|}{$20 \mathrm{~kW} / \mathrm{K}$} & \multicolumn{2}{|c|}{$15 \mathrm{~kW} / \mathrm{K}$} & \multicolumn{2}{|c|}{$20 \mathrm{~kW} / \mathrm{K}$} & & \\
\hline & {$\left[{ }^{\circ} \mathrm{C}\right]$} & {$[\mathrm{kW}]$} & F4 & {$[\mathrm{kW}]$} & F2 & {$[\mathrm{kW}]$} & F4 & {$[\mathrm{kW}]$} & F1 & {$[\mathrm{kW}]$} & F2 & {$[\mathrm{kW}]$} & F1 & {$[\mathrm{kW}]$} & F3 \\
\hline$T_{1}$ & 122.5 & & & & & & & & & & 1 & & & & \\
\hline & & & & & & & & & & 75 & $\mathrm{I}$ & & & & \\
\hline$T_{2}$ & 117.5 & & & & & & & & & & 1 & & & & \\
\hline & & & & & & & & & & 300 & 1 & & & -600 & $\uparrow$ \\
\hline$T_{3}$ & 97.5 & & & & & & 1 & & & & 1 & & & & 1 \\
\hline & & & & & & 41 & $\mathrm{I}$ & & & 25 & $\downarrow$ & & & -50 & I \\
\hline $\mathbf{T}_{4}$ & 95.85 & & & & 1 & & 1 & & & & & & & & 1 \\
\hline & & & & 50 & 1 & 84 & 1 & & & & & & & \begin{tabular}{|l|}
-101 \\
\end{tabular} & 1 \\
\hline$T_{5}$ & 92.5 & & & & 1 & & 1 & & & & & & & & 1 \\
\hline & & & & 300 & 1 & 500 & $\mathrm{I}$ & & & & & -400 & $\uparrow$ & -600 & 1 \\
\hline$T_{6}$ & 72.5 & & & & 1 & & 1 & & & & & & 1 & & 1 \\
\hline & & & & 345 & 1 & 575 & $\downarrow$ & -460 & $\uparrow$ & & & & & & \\
\hline $\mathbf{T}_{7}$ & 49.5 & & 1 & & 1 & & & & 1 & & & & & & \\
\hline & & 300 & $\downarrow$ & 180 & 1 & & & -240 & $I$ & & & & & & \\
\hline $\mathbf{T}_{8}$ & 37.5 & & & & 1 & & & & $I$ & & & & & & \\
\hline & & & & 300 & $\downarrow$ & & & -400 & 1 & & & & & & \\
\hline $\mathbf{T}_{9}$ & 17.5 & & & & & & & & 1 & & & & & & \\
\hline & & & & & & & & -100 & 1 & & & & & & \\
\hline $\mathbf{T}_{10}$ & 12.5 & & & & & & & & 1 & & & & & & \\
\hline & $\Sigma$ & 300 & & 1175 & & 1200 & & -1200 & & 400 & & -400 & & -1350 & \\
\hline
\end{tabular}

Figure 6. HSDT of the exemplary four-stream HEN.

\subsection{Construction of the METD and Targeting of HP Potential}

The METD is constructed by stacking each individual EGCC (cf. Section 3.3) by superimposing them on top of one another. For each HEX the tabular values for $\dot{H}_{i}$ are calculated according to the last column of Figure $5 \mathrm{c}$ and Equation (10).

$$
\dot{\mathrm{H}}_{\mathrm{i}(\mathrm{j})}^{*}=\dot{\mathrm{H}}_{\mathrm{i}(\mathrm{j})}+\dot{\mathrm{H}}_{\mathrm{i}(\mathrm{j}-1)}
$$

While $\dot{\mathrm{H}}_{\mathrm{i}}$ represents the heat cascade of each HEX in a certain temperature interval $\mathrm{i}, \dot{\mathrm{H}}_{\mathrm{i}}{ }^{*}$ according to Equation (11) represents the heat cascade of superimposed $\dot{\mathrm{H}}$ values. Index $i$ refers to each temperature level and $j$ to each EGCC. Using the $\dot{H}_{i}$ data, the outline of each EGCC can be plotted to the form of the METD with shifted temperature $\mathrm{T}^{*}$ on the $Y$-axis and $\dot{H}_{i}{ }^{*}$ on the $X$-axis (cf. Figure 7c). The required order of $\dot{H}_{\mathrm{i}}$ columns below the Pinch is coolers, followed by heaters and, lastly recovery HEX. Above the Pinch is to begin with the heaters, followed by coolers and finally recovery HEX.
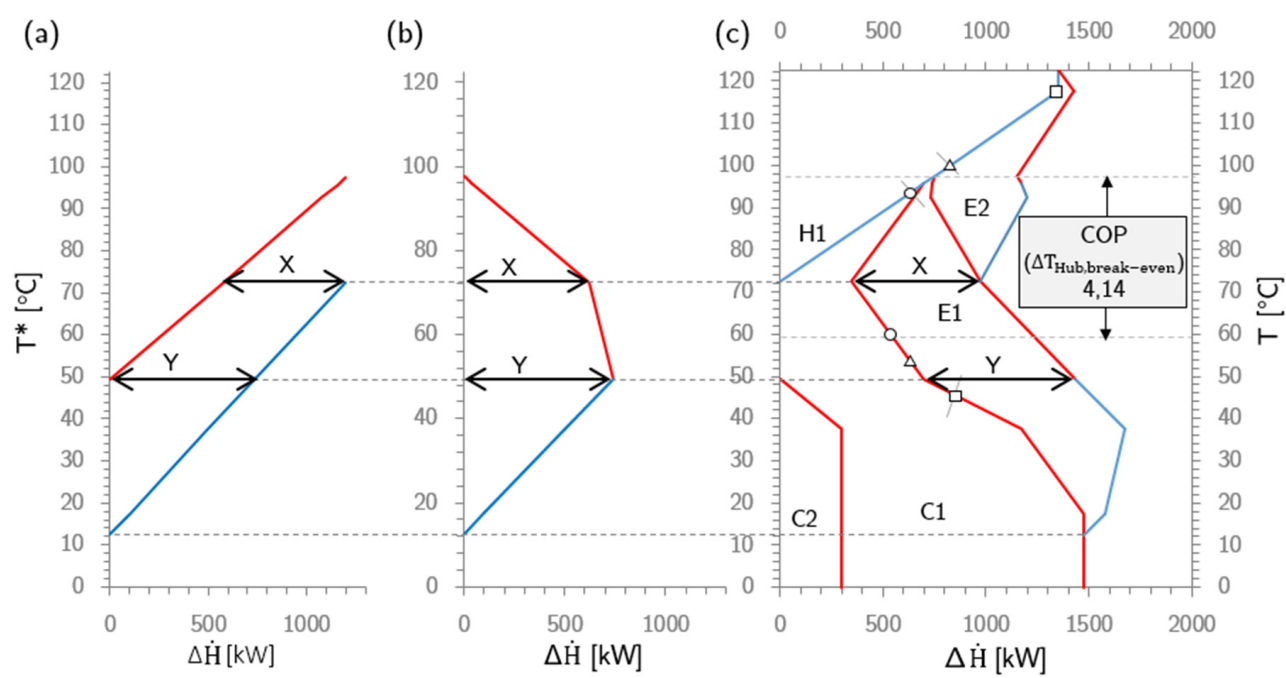

Figure 7. Development of the METD and targeting of technical (minimum: circle marker; maximum: square marker) and economical (triangle marker) HP potential (c) using SCC (a) and EGCC (b) of E1. 
Following these two principles, the cumulated remaining heating and cooling demand can be represented at the appropriate temperature level, which is a prerequisite for correctly implementing the COP curve according to Section 3.1. The line colour convention for the METD is blue for segments with heat deficit and red for segments with heat surplus. The potential for a VHTHP for the present HEN lies between its minimum temperature difference and the maximum heating demand of H1. Each HP bridge option below $\Delta \mathrm{T}_{\text {lift,break-even }}=38 \mathrm{~K}$ (cf. Figure $7 \mathrm{c}$ ), represents an economically more advantageous supply by a HP than by a SGB.

\subsection{Identification of Heat Pump Bridge options}

Like the retrofit bridge, the HP bridge represents a link between a cooler and a heater. However, the difference is that, against the thermodynamic feasible heat cascade direction of a retrofit bridge, a heat surplus can only be associated with a heat deficit of a higher temperature interval. Within the framework of this retrofit problem, a link can be drawn between $\mathrm{C} 2 / \mathrm{C} 1$ and $\mathrm{H} 1$. The determination of the integration points is carried out analogous to the procedure described in Section 3.1 using the COP curves, although the GCC is replaced by the METD. In principle, the following guidelines apply to the design of the HP bridge within the potential range represented in Figure $7 \mathrm{c}$ for a certain reference variable:

- $\Delta \mathrm{T}_{\text {lift }}$ of the HP bridge should be kept as small as possible and cover as much heat of the $\mathrm{HU}$ and $\mathrm{CU}$ as possible.

- If possible, the HP should completely cover the demand of the stream-specific HU or CU to keep the number of utilities in the HEN little

- The HP should extract (surplus) heat below the Pinch temperature and feed it in above the Pinch temperature

\subsection{Identification of Retrofit Bridges}

Heat recovery pockets are formed and illustrated in GCCs for the case of heat deficit below the Pinch and/or heat surpluses above the Pinch (cf. green area Figure 1). The area of a pocket is proportional to HEX's duty and available temperature driving force. Large pocket areas under the curve indicate a high thermodynamic driving force. Small pockets areas point out that a match is already very efficient with temperature differences similar to the minimum. Aim of the HPBA (steps 6 to 9 ) is to minimise pocket area by operating HEX at minimum approach temperature $\Delta \mathrm{T}_{\min }$ in order to efficiently exploit available temperature driving force.

If the pocket crosses the Pinch (e.g., Hot Stream in E1 in Figure 7), this indicates that existing stream matches in an HEX can be reintegrated to transfer surplus heat that is cooled across the Pinch to a heat deficit. In this way pockets representing available heat surplus or deficit can be resolved or reduced, thereby reducing the utility's consumption. This is achieved by optimizing the already integrated HEXs using the HSDT and is defined in steps 6 till 8 of the method (cf. Figure 3). For the identification of retrofit bridges (step 8) the following principles were defined by Lal et al. [32] and applied additionally to step 6 and 7:

- A retrofit bridge only links one CU with one HU.

- A bridge is a series of connections between heat surpluses and heat deficits

- A heat surplus can only be associated with a heat deficit of the same or lower temperature interval. This is based on the Second Law of Thermodynamics.

- In the METD, a retrofit bridge always cascade heat in upward temperature direction.

- Since a heat surplus can only be linked to a heat deficit whose temperature interval is at an equal or lower temperature level, the first step is to identify the areas that overlap horizontally. The capacity of the bridge depends on the minimum available heat duty along all temperature intervals and also determines the reduced heat demand of the $\mathrm{CU}$ and $\mathrm{HU}$. 
- In contrast to the principles of conventional HEN design, the matching of streams in the lower (below the Pinch) or upper (above the Pinch) temperature range is conceivable. In this case, the required temperature level of the external cooling and heating demands are approximated which also favours the efficient integration of HPs.

In principle, this can be done iteratively as long as there is still heat recovery potential to be tapped. The heat recovery potential can be read from the distance of the right-handed METD curve to the $Y$-axis at Pinch temperature level (cf. Figure 7c).

\section{Results}

The stepwise application of the introduced method is shown below using the muchcited, illustrative example from Klemeš et al. [37].

\subsection{Illustrative Example}

According to the existing design (cf. Figure 8) of the illustrative example all streams in the HEN are matched with external cooler/heater or heat recovery HEX and balanced to achieve the target temperatures of the respective streams. The four-stream retrofit problem is scaled to a temperature level suitable for HP.

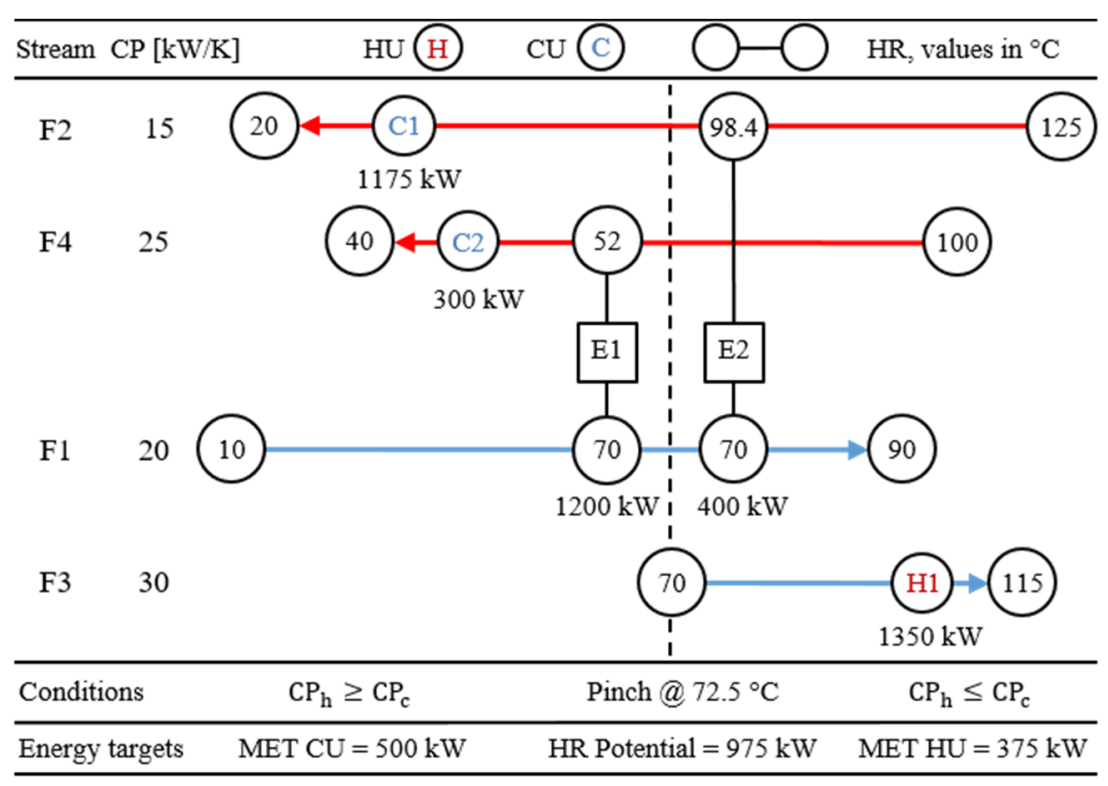

Figure 8. Grid diagram of the illustrative four-stream HEN [37].

The underlying HEN contains two HEX E1 and E2 which already contribute to heat recovery. In total, cold utilities (CU) 1 and 2 indicate a cooling demand of $1475 \mathrm{~kW}$ and hot utility (HU) 1 a heating demand of $1350 \mathrm{~kW}$. However, the Problem Table Algorithm (PTA) determine minimum energy targets (MET) of $500 \mathrm{~kW}$ for cooling and $375 \mathrm{~kW}$ for heating as well as a Pinch temperature of $72.5^{\circ} \mathrm{C}$. The difference between the MET to be understood as a thermodynamic benchmark and the real energy demand lay in the heat recovery potential of $975 \mathrm{~kW}$. The deviation can be explained by inefficient integration of HEX, which violates the Pinch rules.

For the present HEN design, $61 \%$ of the heat demand $\mathrm{H} 1$ can be covered economically by a HP, whereas $79 \%$ were expected according to the common procedure based on the GCC (cf. Figure 4a). Figure 9 shows two HP bridge options completely meeting heating demand based on the METD. The reference variable is $\mathrm{H} 1$ with $\mathrm{T}_{\mathrm{t}, \text { Sink }}^{*}=117.5^{\circ} \mathrm{C}$ and $\dot{\mathrm{Q}}_{\mathrm{t}, \mathrm{Sink}, \mathrm{H} 1}=1350 \mathrm{~kW}$. Due to the temperature level $\left(>100^{\circ} \mathrm{C}\right)$ a VHTHP (see Table A2) is selected. In contrast to the conventional method, the COP curve now allows the selection of various integration options based on knowledge of the individual streams. 

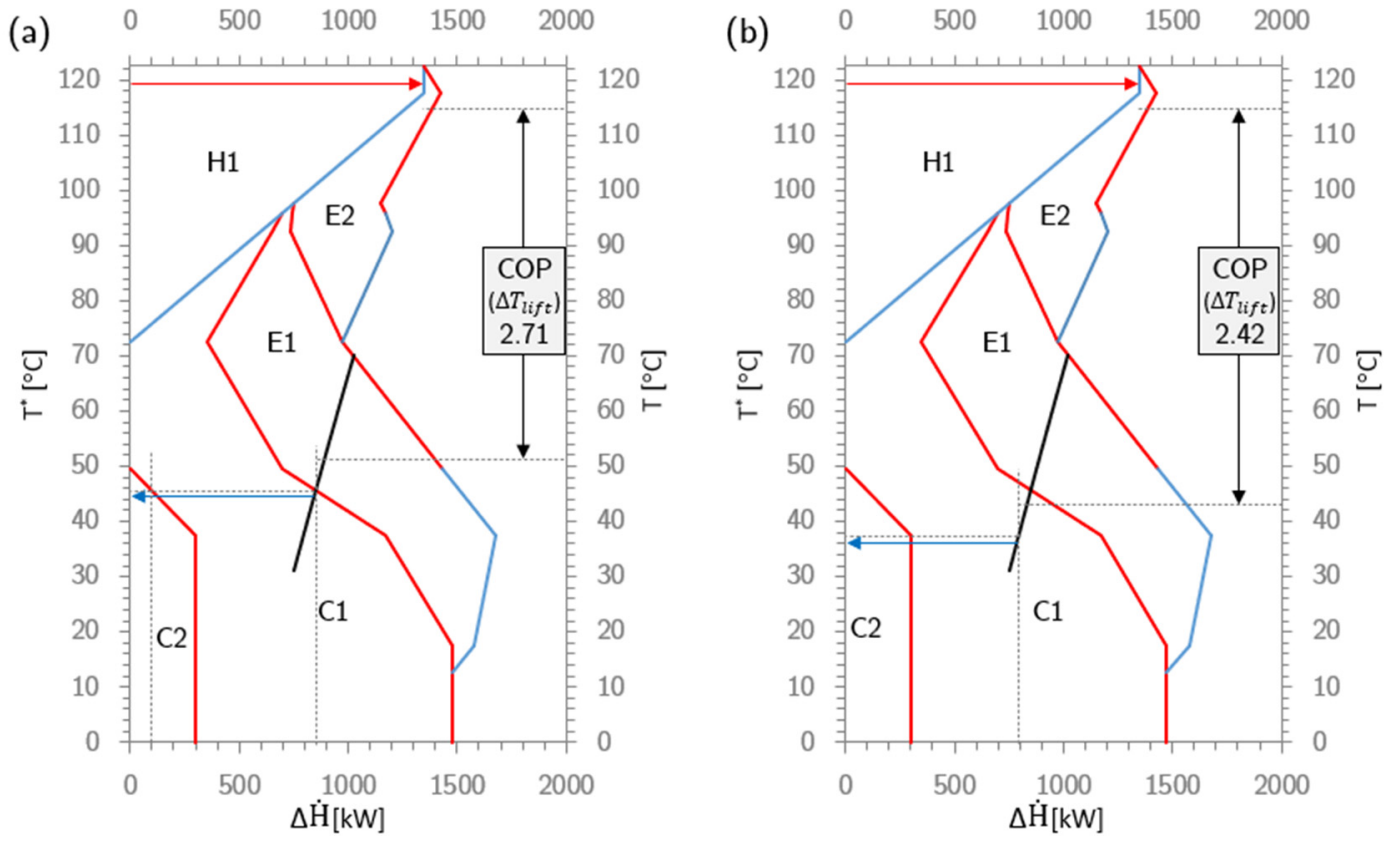

Figure 9. Targeting of HP bridges: (a) Part coverage of $\mathrm{C} 1$ and $\mathrm{C} 2$, (b) complete coverage of $\mathrm{C} 2$.

It is conceivable, as shown in Figure 9a, to identify the minimum temperature lift for the desired heating duty and temperature by the intersection with $\mathrm{C} 1$. This leads to the fact that $\mathrm{C} 1$ and $\mathrm{C} 2$ are only partially covered and two utility exchangers are necessary $(\mathrm{CU} 1=390 \mathrm{~kW} ; \mathrm{CU} 2=210 \mathrm{~kW})$. If the strategy is to cover a utility like C2 completely and save one HEX, this leads to a higher $\Delta \mathrm{T}_{\text {lift }}$, consequently lower COP and a CU1 of $660 \mathrm{~kW}$.

\subsection{First Retrofit Loop}

The heat recovery potential is still $975 \mathrm{~kW}$, indicated by the horizontal distance of the right-handed METD curve to the $Y$-axis at Pinch temperature in Figures $7 \mathrm{c}$ and 9. It is therefore recommended to tap further heat recovery potential by applying steps $6-8$ of the HPBA method.

\subsubsection{Minimisation of $\Delta \mathrm{T}_{\mathrm{HEX}}$}

Step 6 includes the reduction of $\Delta \mathrm{T}_{\mathrm{HEX}}$. This is first illustrated using $\mathrm{E} 1$ in Figure 10a,b as an example. The identification of a possible reduction consists of the investigation of the temperature intervals of the utility streams, which are already integrated. In the case of E1 these are the flows F4 and F1. A prerequisite for the reduction of $\Delta \mathrm{T}_{\mathrm{HEX}}$ is that there must be a heat surplus for hot streams, which is covered by $\mathrm{CU}$ at a lower temperature level. For cold streams, the reverse analogy applies. Accordingly, there must be a heat deficit, which is covered by HUs at a higher temperature level. The reduction of $\Delta \mathrm{T}_{\mathrm{HEX}}$ is shown in Figure 10. It can be seen in Figure 10a that the proportion of F4 integrated in E1 lies in the temperature interval $\mathrm{T}_{3}-\mathrm{T}_{7}$ representing a cross-Pinch heat transfer. Similarly, a further proportion of F4 is available at a lower temperature interval, which is covered by $\mathrm{C} 2$ and enables a shift in demand (green areas in Figure 10a). For E1 this means that the outlet temperature of $\mathrm{F} 4$ can be shifted to the temperature of $\mathrm{T}_{7}$ within the HEX. This results in a shift of the cooling demand of $300 \mathrm{~kW}$ and is covered by C2 after modification in the temperature interval $\mathrm{T}_{4}-\mathrm{T}_{7}$ (Figure $10 \mathrm{~b}$ ), which is then used to cover the heat deficit of F3 above the Pinch (Figure 11b). Likewise, the cold stream F1 in the grey-shaded fields within the temperature interval $\mathrm{T}_{5}-\mathrm{T}_{6}$ indicates a possible shift to a higher temperature level (Figure 10a). 
(a)

\begin{tabular}{|c|c|c|c|c|c|c|c|c|c|}
\hline \multirow{3}{*}{$\mathbf{T}_{\mathrm{i}}$} & \multirow{2}{*}{$\mathbf{T}^{*}$} & \multicolumn{2}{|c|}{$\mathrm{C} 2$} & \multicolumn{2}{|l|}{ C1 } & \multicolumn{4}{|c|}{ E1 } \\
\hline & & \multicolumn{2}{|c|}{$25 \mathrm{~kW} / \mathrm{K}$} & \multicolumn{2}{|c|}{$15 \mathrm{~kW} / \mathrm{K}$} & \multicolumn{2}{|c|}{$25 \mathrm{~kW} / \mathrm{K}$} & \multicolumn{2}{|c|}{$20 \mathrm{~kW} / \mathrm{K}$} \\
\hline & {$\left[{ }^{\circ} \mathrm{C}\right]$} & {$[\mathrm{kW}]$} & F4 & [kW] & F2 & [kW] & F4 & [kW] & $\mathbf{F} 1$ \\
\hline $\mathbf{T}_{1}$ & 122.5 & & & & & & & & \\
\hline$T_{2}$ & & & & & & & & & \\
\hline & $11 / .5$ & & & & & & & & \\
\hline$T_{3}$ & 97.5 & & & & & & 1 & & \\
\hline & & & & & & 41 & 1 & & \\
\hline$T_{4}$ & 95.85 & & & & 1 & & 1 & & \\
\hline & & & & 50 & I & 84 & 1 & & \\
\hline$T_{5}$ & 92.5 & & & & I & & 1 & & \\
\hline & & & & 300 & I & 500 & 1 & & \\
\hline$T_{6}$ & 72.5 & & & & $\mathrm{I}$ & & $\begin{array}{ll}1 \\
\end{array}$ & & \\
\hline & & & & 345 & \begin{tabular}{|l|}
1 \\
\end{tabular} & 575 & $\downarrow$ & -460 & $\uparrow$ \\
\hline $\mathbf{T}_{7}$ & 49.5 & & 4. & $\ldots \ldots \ldots$ & $-1-1$ & $\nabla$ & & & I \\
\hline & & 300 & $\downarrow$ & 180 & 1 & & & -240 & I \\
\hline$T_{8}$ & 37.5 & & & & I & & & & 1 \\
\hline & & & & 300 & $\downarrow$ & & & -400 & 1 \\
\hline$T_{9}$ & 17.5 & & & & & & & & $I$ \\
\hline & & & & & & & & -100 & 1 \\
\hline $\mathbf{T}_{10}$ & 12.5 & & & & & & & & I \\
\hline & $\Sigma$ & 300 & & 1175 & & 1200 & & -1200 & \\
\hline
\end{tabular}

(b)

\begin{tabular}{|c|c|c|c|c|c|c|c|c|c|}
\hline \multirow{3}{*}{\begin{tabular}{|l}
$\mathbf{T}_{\mathbf{i}}$ \\
\end{tabular}} & \multirow{3}{*}{$\frac{\mathbf{T}^{*}}{\left[^{\circ} \mathrm{Cl}\right.}$} & \multirow{2}{*}{\multicolumn{2}{|c|}{$\frac{\text { C2 }}{25 \mathrm{~kW} / \mathrm{K}}$}} & \multirow{2}{*}{\multicolumn{2}{|c|}{$\begin{array}{c}\text { C1 } \\
15 \mathrm{~kW} / \mathrm{K}\end{array}$}} & \multicolumn{4}{|c|}{ E1 } \\
\hline & & & & & & \multicolumn{2}{|c|}{$25 \mathrm{~kW} / \mathrm{K}$} & \multicolumn{2}{|c|}{$20 \mathrm{~kW} / \mathrm{K}$} \\
\hline & & {$[\mathrm{kW}]$} & 74 & {$[\mathrm{~kW}]$} & $\mathbf{F}_{2}$ & {$[\mathrm{~kW}]$} & F4 & & \\
\hline$T_{1}$ & 122.5 & & & & & & & & \\
\hline & & & & & & & & & \\
\hline$T_{2}$ & 117.5 & & & & & & & & \\
\hline$T_{3}$ & 9015 & & & & & & & & \\
\hline & & & & & & & & & \\
\hline$T_{4}$ & 97.5 & & 1 & & & & & & \\
\hline & & 41 & I & & & & & & \\
\hline$T_{5}$ & 95.85 & & 1 & & & & & & \\
\hline & & 84 & I & 50 & I & & & & \\
\hline$T_{6}$ & 92.5 & & 1 & & I & & & & \\
\hline & & 175 & 止 & -105 & + & & & & \\
\hline$T_{7}$ & 85.5 & & & & I & & I & & \\
\hline & & & & 195 & I & 325 & 1 & & \\
\hline$T_{8}$ & 72.5 & & & & I & & 1 & & \\
\hline & & & & 345 & I & $\begin{array}{l}575 \\
\end{array}$ & 1 & -460 & $\uparrow$ \\
\hline$T_{9}$ & 49.5 & & & & 1 & & 1 & & \\
\hline & & & & 180 & I & 300 & $\downarrow$ & -240 & 11 \\
\hline$T_{10}$ & 37.5 & & & & I & & & & 1 \\
\hline & & & & 131 & 1 & & & -175 & 1 \\
\hline$T_{11}$ & 28.75 & & & & 1 & & & & 1 \\
\hline & & & & 169 & $\downarrow$ & & & -225 & . \\
\hline$T_{12}$ & 17.5 & & & & & & & & 4 \\
\hline & & & & & & & & -100 & 1 \\
\hline$T_{13}$ & 12.5 & & & & & & & & 1 \\
\hline & $\Sigma$ & 300 & & 1175 & & 1200 & & -1200 & \\
\hline
\end{tabular}

Figure 10. Illustration of reducing $\Delta \mathrm{T}_{\mathrm{HEX}}$ within $\mathrm{E} 1$ before the shift in demand (a) and after (b).

(a)

\begin{tabular}{|c|c|c|c|c|c|c|c|c|c|c|c|}
\hline \multirow{3}{*}{$\mathbf{T}_{\mathbf{i}}$} & \multirow{2}{*}{$\mathbf{T}^{*}$} & \multicolumn{2}{|c|}{$\mathrm{C} 2$} & \multicolumn{2}{|c|}{ C1 } & \multicolumn{4}{|c|}{ E1 } & \multicolumn{2}{|c|}{ H2 } \\
\hline & & \multicolumn{2}{|c|}{$25 \mathrm{~kW} / \mathrm{K}$} & \multicolumn{2}{|c|}{$15 \mathrm{~kW} / \mathrm{K}$} & \multicolumn{2}{|c|}{$25 \mathrm{~kW} / \mathrm{K}$} & \multicolumn{2}{|c|}{$20 \mathrm{~kW} / \mathrm{K}$} & \multicolumn{2}{|c|}{$20 \mathrm{~kW} / \mathrm{K}$} \\
\hline & {$\left[{ }^{\circ} \mathrm{C}\right]$} & {$[\mathrm{kW}]$} & F4 & {$[\mathrm{kW}]$} & F2 & {$[\mathrm{kW}]$} & F4 & {$[\mathrm{kW}]$} & F1 & {$[\mathrm{kW}]$} & F1 \\
\hline$T_{6}$ & 92.5 & & 1 & & I & & & & & & \\
\hline & & 175 & $\downarrow$ & 105 & 1 & & & & & & \\
\hline $\mathbf{T}_{7}$ & 85.5 & 4 & & 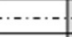 &.-++ & - & 1 & & & & \\
\hline & & & & 195 & I & 325 & 1 & & & & \\
\hline$T_{8}$ & 72.5 & & & & I & & 1 & & & & \\
\hline & & & & 345 & 1 & 575 & 1 & -460 & $\uparrow$ & & \\
\hline $\mathbf{T}_{9}$ & 49.5 & & & & I & & 1 & & 1 & & \\
\hline & & & & 180 & 1 & 300 & $\downarrow$ & -240 & 1 & & \\
\hline$T_{10}$ & 37.5 & & & & 1 & & & & 1 & & \\
\hline & & & & 131 & 1 & & & -175 & 1 & & \\
\hline$T_{11}$ & 28.75 & & & & 1 & & & & 1 & & \\
\hline & & & & 169 & $\downarrow$ & & & -225 & 1 & & \\
\hline$T_{12}$ & 17.5 & & & & & & & $\cdots$ & +1 & $\rightarrow$ & \\
\hline & & & & & & & & -100 & 1 & & \\
\hline$T_{13}$ & 12.5 & & & & & & & & 1 & & \\
\hline & $\Sigma$ & 300 & & 1175 & & 1200 & & -1200 & & 0 & \\
\hline
\end{tabular}

(b)

\begin{tabular}{|c|c|c|c|c|c|c|c|c|c|}
\hline \multirow{3}{*}{$\mathbf{T}_{\mathbf{i}}$} & & \multicolumn{2}{|c|}{ C2 } & \multicolumn{2}{|c|}{ C1 } & \multicolumn{2}{|c|}{ H2 } & \multicolumn{2}{|l|}{ H1 } \\
\hline & & \multicolumn{2}{|c|}{$25 \mathrm{~kW} / \mathrm{K}$} & \multicolumn{2}{|c|}{$15 \mathrm{~kW} / \mathrm{K}$} & \multicolumn{2}{|c|}{$20 \mathrm{~kW} / \mathrm{K}$} & \multicolumn{2}{|c|}{$30 \mathrm{~kW} / \mathrm{K}$} \\
\hline & {$\left[{ }^{\circ} \mathrm{C}\right]$} & {$[\mathrm{kW}]$} & F4 & {$[\mathrm{kW}]$} & F2 & {$[\mathrm{kW}]$} & F1 & {$[\mathrm{kW}]$} & F3 \\
\hline $\mathbf{T}_{1}$ & 122.5 & & & & & & & & \\
\hline & & & & & & & & & \\
\hline$T_{2}$ & 117.5 & & & & & & & & \\
\hline & & & & & & & & -550.5 & $\uparrow$ \\
\hline$T_{3}$ & 99.15 & & & & & & & & I \\
\hline & & & & & & & & -49.5 & 1 \\
\hline $\mathbf{T}_{4}$ & \begin{tabular}{l|}
97.5 \\
\end{tabular} & & 1 & & & & & & 1 \\
\hline & & 41 & 1 & & & & & -49.5 & 1 \\
\hline$T_{5}$ & 95.85 & & + & $\exists$ & E4 & & & $\rightarrow$ & 1 \\
\hline & & 84 & 1 & 50 & $T$ & & & -100.5 & 1 \\
\hline$T_{6}$ & 92.5 & & 1 & & 1 & & & & 1 \\
\hline & & 175 & 1 & 105 & 1 & & & -210 & 1 \\
\hline $\mathbf{T}_{7}$ & 85.5 & & 1 & & 1 & & & & I \\
\hline & & 325 & $\downarrow$ & 195 & 1 & & & -390 & 1 \\
\hline$T_{s}$ & 72.5 & & & & 1 & & & & 1 \\
\hline & & & & 345 & 1 & & & & \\
\hline $\mathbf{T}_{9}$ & 49.5 & & & & 1 & & & & \\
\hline & & & & 180 & & & & & \\
\hline $\mathbf{T}_{10}$ & 37.5 & & & & & & & & \\
\hline & & & & 131 & & & & & \\
\hline$T_{11}$ & 28.75 & & & & & & & & \\
\hline & & & & 169 & $\downarrow$ & -225 & $\uparrow$ & & \\
\hline$T_{12}$ & 17.5 & & & & & & 1 & & \\
\hline & & & & & & -100 & 1 & & \\
\hline $\mathbf{T}_{13}$ & 12.5 & & & & & & 1 & & \\
\hline & $\Sigma$ & 625 & & 1175 & & -325 & & -1350 & \\
\hline
\end{tabular}

Figure 11. Correction of the cross-Pinch violation in E1 (a) and design of new retrofit bridges E3 and E4 (b). 


\subsubsection{Removal of Cross-Pinch Violations}

The minimisation of $\Delta \mathrm{T}_{\mathrm{HEX}}$ is followed by the elimination of cross-Pinch violations. They result from incorrect HEX integration across the Pinch. This leads to additional heating and by the same amount higher cooling demands. The removal of these violations is therefore of great importance for the overall efficiency. If a hot stream from a HEX crosses the red line or a cold stream crosses the blue line in Figure 11 representing the hot and cold Pinch, the HEX commits a cross-Pinch violation. The correction of the cross-Pinch violation is performed according to the following pattern. First, the affected HEX is fictitiously divided into hot and cold stream. Then, the divided streams are reconnected, taking into account the Pinch temperature. Thus, the Pinch-exceeding demand is extracted from the HEX and assigned to heat recovery HEXs or coolers respectively heaters. With reference to E1, the scenario shown in Figure 11a results, which represents a heat transfer across the Pinch temperature by F4.

With the described procedure for the correction of cross-Pinch violations, the Pinch exceeding heat duty of $325 \mathrm{~kW}$ would be transferred from $\mathrm{F} 4$ in the temperature interval $\mathrm{T}_{7}-\mathrm{T}_{8}$ to $\mathrm{C} 2$ (cf. green area in Figure 11a). However, to compensate the heat duties within $\mathrm{E} 1$, the stream F1 must also be adjusted by the same duty. Thus, in the sense of minimising $\Delta \mathrm{T}_{\mathrm{HEX}}, 325 \mathrm{~kW}$ are transferred equally from $\mathrm{F} 1$ within the temperature interval $\mathrm{T}_{11}-\mathrm{T}_{13}$ to H2 (cf. green area in Figure 11a). The result is a HEX E1 that is re-integrated into the HEN below the Pinch according to the rules of PA.

After the correction of the cross-Pinch violation of E1, the identification of the retrofit bridges in Figure 11b follows. The rules of the BA according to Section 3.7 [32] aiming a minimum $\triangle \mathrm{T}_{\mathrm{HEX}}$ are used for this. In this case two retrofit bridges can be identified. The first one (E3) links C1 with $\mathrm{H} 2$ and the second (E4) C2 with H1. The smallest available heat duty represents the bottleneck of the bridge and is responsible for the size of the respective associated HEX. Therefore, the heat duty transferred in E3 is $325 \mathrm{~kW}$ and in E4 $625 \mathrm{~kW}$. This procedure allows $\mathrm{C} 1$ to be placed at a higher temperature level, which increases the efficiency of a possible HP bridge, as the following section confirms.

\subsubsection{Heat Pump and Heat Exchanger Network Design of First Retrofit Loop}

The first retrofit loop according to Figure 3 results in a HEN as shown in Figure 12a with the additional HEX E3 and E4. The modifications reduce the CU demand from 1475 to $850 \mathrm{~kW}$ and equally reduced the HU from 1350 to $725 \mathrm{~kW}$. In addition, C2 is no longer required in this configuration. Furthermore, by minimising $\Delta \mathrm{T}_{\mathrm{HEX}}$, an approximation of the heating and cooling demand to the right-handed curve can be determined.

(a)



(b) $\quad 0 \quad 200 \quad 400 \quad 600 \quad 800 \quad 1000$



Figure 12. (a) Final HEN after first retrofit loop and (b) illustration of the technical (minimum: circle marker; maximum: square marker) and economic (triangle marker) HP potential in the METD. 
Figure $12 \mathrm{~b}$ targets further HP bridge options. With a COP of $3.44\left(\Delta \mathrm{T}_{\text {lift }}=52.25 \mathrm{~K}\right)$, the HP fully covers the heating demand (square marker) and reduces CU1 from $850 \mathrm{~kW}$ to $320 \mathrm{~kW}$. In addition to the increase of the heat recovery, the modifications made so far even allow an improvement of the HP efficiency. However, a HP at break-even achieves a higher relative coverage rate (61\% to $79 \%)$ than in the initial state of the HEN.

\subsection{Second Retrofit Loop}

Figure $12 \mathrm{~b}$ indicates a remaining heat recovery potential of $350 \mathrm{~kW}$. Since the METD (cf. Figure $12 \mathrm{~b}$ ) shows improvement potential for $\mathrm{E} 2$ due to the large $\Delta \mathrm{T}_{\mathrm{E} 2}$, a second retrofit loop for increasing heat recovery can be examined.

\subsubsection{Minimisation of $\Delta \mathrm{T}_{\mathrm{HEX}}$}

The corresponding HSDT (Figure 13a) shows that the surplus heat in $\mathrm{C} 1$ at a lower temperature level can be used to reduce $\Delta \mathrm{T}_{\mathrm{E} 2}$. Thereby the heat surplus of $400 \mathrm{~kW}$ within $\mathrm{E} 2$ shifts from the temperature interval $\mathrm{T}_{1}-\mathrm{T}_{5}$ to $\mathrm{T}_{5}-\mathrm{T}_{8}$. This shift minimises the temperature gradient within E2 and shifts the heat surplus from $\mathrm{C} 1$ to a higher temperature level, resulting in another potential retrofit bridge. The step of cross-Pinch correction is not necessary in the case of E2, as the entire heat transfer is above the Pinch temperature. The resulting retrofit possibility is shown in Figure 13b. It is limited by the available heat duty of $350 \mathrm{~kW}$ in $\mathrm{C} 1$ and links the heat surplus in $\mathrm{C} 1$ with the heat deficit in H1. Since H1 has a higher $\Delta \dot{\mathrm{H}}_{23}$ in the interval $\mathrm{T}_{2}-\mathrm{T}_{3}$, the split of the heating demand is necessary to design the $\mathrm{HP}$ bridge at a minimum $\Delta \mathrm{T}_{\mathrm{HEX}}$. As a result, the original utility $\mathrm{H} 1$ is divided into H1a and H1b.

(a)

\begin{tabular}{|c|c|c|c|c|c|c|c|c|c|c|c|}
\hline \multirow{3}{*}{$\mathbf{T}_{\mathbf{i}}$} & \multirow{2}{*}{$\mathbf{T}^{*}$} & \multicolumn{2}{|c|}{$\mathrm{C} 2$} & \multicolumn{2}{|c|}{ C1 } & \multicolumn{4}{|c|}{ E2 } & \multicolumn{2}{|c|}{ H1 } \\
\hline & & \multicolumn{2}{|c|}{$25 \mathrm{~kW} / \mathrm{K}$} & \multicolumn{2}{|c|}{$15 \mathrm{~kW} / \mathrm{K}$} & \multicolumn{3}{|c|}{\begin{tabular}{|l|l}
$15 \mathrm{~kW} / \mathrm{K}$ & $20 \mathrm{~kW} / \mathrm{K}$
\end{tabular}} & $\mathrm{V} / \mathrm{K}$ & \multicolumn{2}{|c|}{$30 \mathrm{~kW} / \mathrm{K}$} \\
\hline & {$\left[{ }^{\circ} \mathrm{C}\right]$} & {$[\mathrm{kW}]$} & F4 & {$[\mathrm{kW}]$} & F2 & {$[\mathrm{kW}]$} & $\mathbf{F} 2$ & {$[\mathrm{~kW}]$} & F1 & {$[\mathrm{kW}]$} & F3 \\
\hline \multirow{2}{*}{$\mathbf{T}_{1}$} & 122.5 & & & & & & 1 & & & & \\
\hline & & & & & & 75 & 1 & & & & \\
\hline \multirow{2}{*}{$T_{2}$} & 117.5 & & & & & & 1 & & & & \\
\hline & & & & & & 275 & 1 & & & -550 & $\uparrow$ \\
\hline \multirow[t]{2}{*}{$T_{3}$} & 99.15 & & & & & & 1 & & & & I \\
\hline & & & & & & 25 & 1 & & & -50 & 1 \\
\hline \multirow[t]{2}{*}{$T_{4}$} & 97.5 & & & & & & 1 & & & & 1 \\
\hline & & & & & & 25 & $\downarrow$ & & & -50 & 1 \\
\hline \multirow[t]{2}{*}{$T_{5}$} & 95.85 & & & & 1 & & & & & & 1 \\
\hline & & & & 38 & 1 & & & & & -75 & I \\
\hline \multirow[t]{2}{*}{$T_{6}$} & 93.33 & & & -1 & -1. & $\rightarrow$ & & & & & 1 \\
\hline & & & & 12 & 1 & & & & & & \\
\hline \multirow[t]{2}{*}{$\mathbf{T}_{7}$} & 92.5 & & & & 1 & & & & & & \\
\hline & & & & 300 & 1 & & & -400 & $\uparrow$ & & \\
\hline \multirow[t]{2}{*}{$T_{8}$} & 72.5 & & & & 1 & & & & 1 & & \\
\hline & & & & 500 & $\downarrow$ & & & & & & \\
\hline \multirow[t]{2}{*}{$T_{9}$} & 39.17 & & & & & & & & & & \\
\hline & & & & & & & & & & & \\
\hline \multirow[t]{2}{*}{$\mathbf{T}_{10}$} & \begin{tabular}{|l|}
37.5 \\
\end{tabular} & & & & & & & & & & \\
\hline & & & & & & & & & & & \\
\hline \multirow[t]{2}{*}{$\mathbf{T}_{11}$} & 28.75 & & & & & & & & & & \\
\hline & & & & & & & & & & & \\
\hline \multirow[t]{2}{*}{$\mathbf{T}_{12}$} & 17.5 & & & & & & & & & & \\
\hline & & & & & & & & & & & \\
\hline \multirow[t]{2}{*}{$\mathbf{T}_{13}$} & 12.5 & & & & & & & & & & \\
\hline & $\Sigma$ & 0 & & 850 & & 400 & & -400 & & -725 & \\
\hline
\end{tabular}

(b)

\begin{tabular}{|c|c|c|c|c|c|c|c|c|c|c|c|}
\hline \multirow{3}{*}{$\mathbf{T}_{\mathrm{i}}$} & \multirow{2}{*}{$\mathbf{T}^{*}$} & \multicolumn{2}{|c|}{ C2 } & \multirow{2}{*}{\multicolumn{2}{|c|}{\begin{tabular}{|c|} 
C1 \\
$15 \mathrm{~W} / / \mathrm{K}$
\end{tabular}}} & \multirow{2}{*}{\multicolumn{3}{|c|}{ E2 }} & \multirow{2}{*}{\multicolumn{3}{|c|}{ H1 }} \\
\hline & & $25 \mathrm{kV}$ & & & & & & & & & \\
\hline & {$\left[{ }^{\circ} \mathbf{C}\right]$} & {$[\mathrm{kW}]$} & & $\mathrm{kW}]$ & $\mathbf{F 2}$ & {$[\mathrm{kW}]$} & & $\mathrm{kW]} \mathbf{F}$ & $\mathbf{F 1}[\mathrm{k}$ & {$[\mathrm{kW}]$} & $\mid 73$ \\
\hline $\mathbf{T}_{1}$ & 122.5 & & & & & & & & & & \\
\hline & & & & 75 & & & & & & & \\
\hline$T_{2}$ & 117.5 & & & & & & & & & & \\
\hline & & & & 275 & $\Psi$ & & 5 & & & -550 & 1 \\
\hline $\mathbf{T}_{3}$ & 99.15 & & & & & & & & & & \\
\hline & & & & & & 25 & 1 & & & -50 & \\
\hline $\mathbf{T}_{4}$ & 97.5 & & & & & & 1 & & & & 1 \\
\hline & & & & & & 25 & 1 & & & -50 & \\
\hline$T_{5}$ & 95.85 & & & & & & 1 & & & & \\
\hline & & & & & & 38 & 1 & & & -75 & \\
\hline$T_{6}$ & 93.33 & & & & & & 1 & & & & 1 \\
\hline & & & & & & & 1 & & & & \\
\hline $\mathbf{T}_{7}$ & 92.5 & & & & & & 1 & & & & \\
\hline & & & & & & 300 & $\mid \downarrow$ & 400 & & & \\
\hline$T_{8}$ & 72.5 & & & & 1 & & & & 1 & & \\
\hline T9 & 39.17 & & & 500 & $\downarrow$ & & & & & & \\
\hline & & & & & & & & & & & \\
\hline$T_{10}$ & 37.5 & & & & & & & & & & \\
\hline & & & & & & & & & & & \\
\hline 111 & 28.15 & & & & & & & & & & \\
\hline$T_{12}$ & 17.5 & & & & & & & & & & \\
\hline & & & & & & & & & & & \\
\hline$T_{13}$ & 12.5 & & & & & & & & & & \\
\hline & $\Sigma$ & 0 & & 850 & & 400 & & -400 & & -725 & 1 \\
\hline
\end{tabular}

Figure 13. Minimisation of $\Delta \mathrm{T}_{\mathrm{E} 2}$ using the HSDT (a) and identification of the resulting retrofit bridge E5 (b).

\subsubsection{Heat Pump and Heat Exchanger Network Design of Second Retrofit Loop}

The resulting HEN after the second retrofit loop is shown in Figure 14a. H1a and $\mathrm{H} 1 \mathrm{~b}$ cover a HU of $175 \mathrm{~kW}$ at two temperature levels. From an economic point of view, a single heater for $\mathrm{F} 3$ and a corresponding increase of $\Delta \mathrm{T}_{\mathrm{E} 5}$ would be more reasonable. 
For targeting HP bridge options, however, this approach offers further options. First of all, it is generally noticed that the right-handed curve of the METD (Figure 14b) now intersects the $Y$-axis. This implies the achievement of the MET and the exploitation of the full heat recovery potential.

(a)

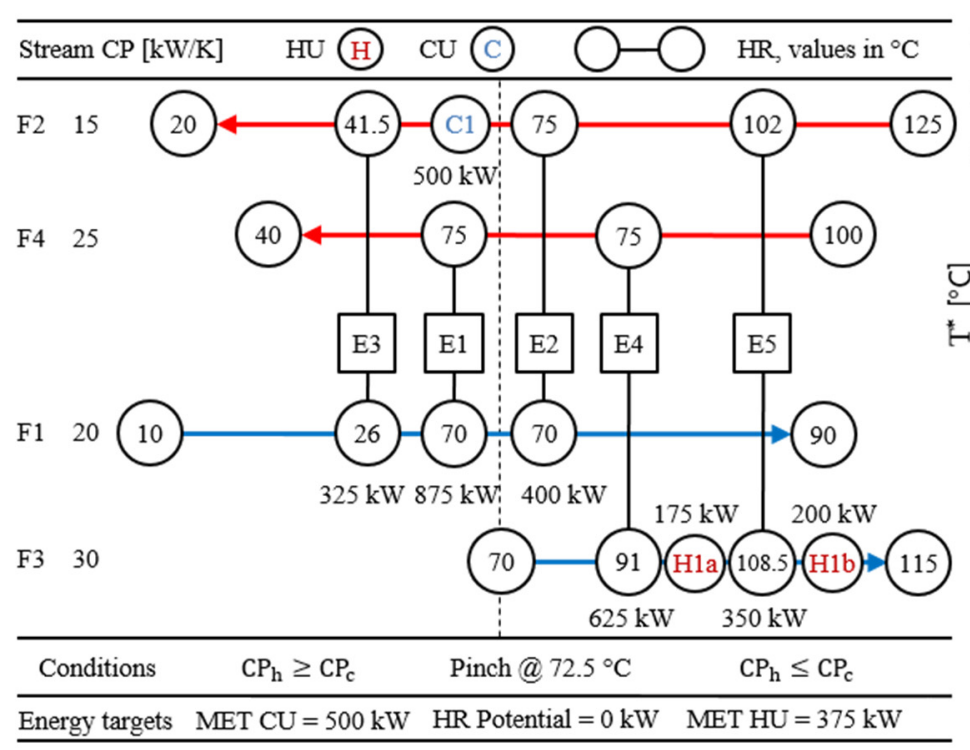

(b) $0 \quad 200 \quad 400 \quad 600 \quad 800$

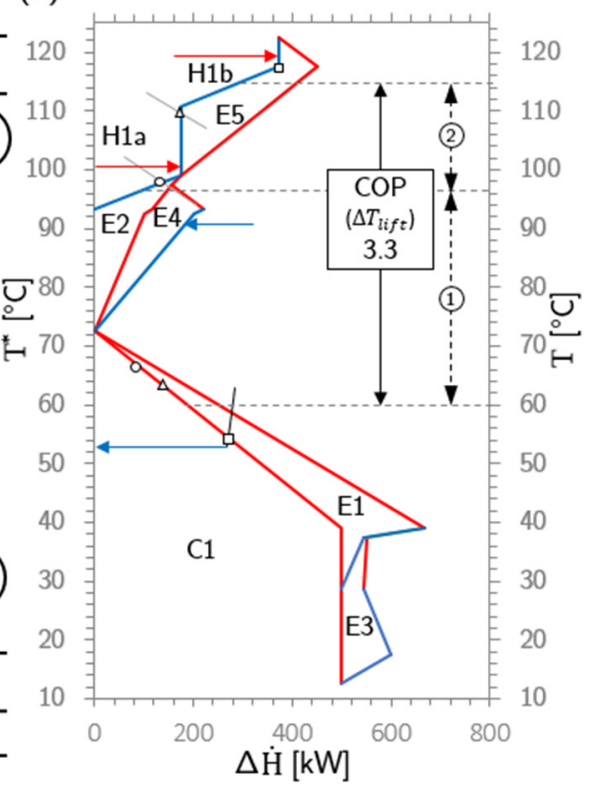

Figure 14. (a) HEN after integration of E5 and (b) illustration of the technical (minimum: circle marker; maximum: square marker) and economic (triangle marker) HP potential in the METD.

Due to the modifications during the HPBA, not only a reduction of the number of coolers but also an increase of the temperature level $\mathrm{C} 1$ can be achieved. This subsequently favours the efficiency of further HP bridge options, as $\Delta \mathrm{T}_{\text {lift }}$ is reduced. Initially, the minimum HP can completely cover the demand H1a at low temperature levels. Due to the low $\Delta \mathrm{T}_{\text {lift }}$ of $25 \mathrm{~K}$, the COP is 6.2. A single-staged HP covering HU1a and HU1b is one HP bridge option with a COP $\left(\Delta \mathrm{T}_{\text {lift }}=54 \mathrm{~K}\right)$ of 3.13.

Because of its layout, the METD provides a detailed insight into the HEN demand distribution and allows targeting of various HP bridge options within the technical potential. Due to the heat demand H1a at an intermediate temperature level, the integration of a two-stage HP to cover the entire heating demand of H1a and H1b is also conceivable. A SHP can provide part of the condensation capacity of the first stage to cover H1a at a medium temperature level $\mathrm{T}_{\mathrm{t}, \mathrm{H} 1 \mathrm{a}}^{*}=99.0^{\circ} \mathrm{C}$. The other part serves as a heat source for the second stage, which covers the heating demand of H1b. Here, a VHTHP is again foreseen for the higher temperature level of $\mathrm{T}_{\mathrm{t}, \mathrm{H} 1 \mathrm{~b}}^{*}=117.5^{\circ} \mathrm{C}$. The outlet temperature of the first stage $\left(T_{h, o u t, 1}\right)$ is also the inlet temperature of the second stage $\left(T_{1, \text { in, }, 2}\right)$. From the temperature difference of $\mathrm{T}_{\mathrm{h}, \mathrm{out}, 2}$ and $\mathrm{T}_{1, \mathrm{in}, 2}$ the COP curve calculates a COP of the second stage of 8.0. Vice versa, this means that the condenser of the first stage must provide $175 \mathrm{~kW}$ of heat to cover $\mathrm{H} 1 \mathrm{a}$ and $175 \mathrm{~kW}$ to operate the second stage. The correlating evaporation capacity of $270 \mathrm{~kW}$ at a COP of 4.4 is obtained from the COP curve according to the known procedure. The technical solution involves division of the condenser outlet flow and cover the heating demand HU1a and the evaporator capacity of the second stage in parallel. The resulting COP of the two-stage HP is 3.3, higher than the single-staged one.

\section{Discussion}

After considering the different HP bridges of the individual retrofit loops, the following findings can be derived. Table 1 gives an overview of the possible integration options within the technical potential and their main characteristics. 
Table 1. Overview of targeted HP bridge (HPB) options based on the HPBA approach for the four-stream HEN.

\begin{tabular}{|c|c|c|c|c|c|}
\hline No. & HP Bridge and Reference Variable & $\begin{array}{c}\text { COP } \\
{[-]}\end{array}$ & $\begin{array}{l}\dot{\mathrm{Q}}_{\text {Cond,HP }} \\
{[\mathrm{kW}]}\end{array}$ & $\begin{array}{c}\mathrm{CU} \\
{[\mathrm{kW}]}\end{array}$ & $\begin{array}{c}\mathrm{HU} \\
{[\mathrm{kW}]}\end{array}$ \\
\hline 1 & $\begin{array}{l}\text { HPB fully covering HU of GCC } \\
\text { square marker in Figure } 4 a\end{array}$ & 3.6 & 375 & 225 & - \\
\hline 2 & $\begin{array}{l}2 \mathrm{HEX}, 1 \text {. HPB minimising } \Delta \mathrm{T}_{\text {lift }} \\
\text { Figure } 9 \mathrm{a}\end{array}$ & 2.71 & 1350 & 600 & - \\
\hline 3 & $\begin{array}{l}2 \text { HEX, 2. HPB reducing the number of utility HEX } \\
\text { Figure } 9 b\end{array}$ & 2.42 & 1350 & 660 & - \\
\hline 4 & $\begin{array}{c}4 \text { HEX, HPB fully covering HU1 } \\
\text { Figure } 12\end{array}$ & 3.44 & 725 & 320 & - \\
\hline 5 & $\begin{array}{l}5 \mathrm{HEX}, 1 \text {. HPB fully covering HU1a und HU1b } \\
\text { Figure } 14 \mathrm{~b}\end{array}$ & 3.13 & 375 & 245 & - \\
\hline 6 & $\begin{array}{c}5 \text { HEX, 2. HPB fully covering HU1a } \\
\text { Figure } 14 b\end{array}$ & 6.2 & 125 & 395 & 200 \\
\hline 7 & 5 HEX, two-stage HPB fully covering HU1a und HU1b, Figure $14 \mathrm{~b}$ & 3.3 (tot) & 375 & 270 & - \\
\hline
\end{tabular}

The increased depth of information of the METD, compared to the GCC, allows on the one hand a more practical integration of a HP and on the other hand provides an essential basis for the correct identification of different HP bridge options. An example of this is the comparison between HPB option 1 and 5. While both integrations aim at the same target value, the COP of the conventional integration using GCC is higher. This is mainly due to the fact that the METD represents actual net enthalpy flow changes of the HU and CU, while the GCC as the thermodynamic optimum is the equivalent of the right-handed curve of the METD. Furthermore, it is not possible to consider process-related or safety-related restrictions of the HEN in the GCC. The METD allows the mapping of these restrictions. This can be understood by comparing option 1 and 2 . The latter takes into account the real existing conditions. The degradation of the COP due to the inefficient temperature gradients in the HEXs and high heating capacity due to the unused heat recovery potential becomes clear. As mentioned above, the METD is also useful to derive different integration possibilities. As an example, integrations 2 and 3, as well as 7, show that the depth of information provided by the METD allows the identification of practical integration points for the HP. While, for example, in 2 the focus is on minimising $\Delta \mathrm{T}_{\text {lift }}$ to achieve the highest possible COP, in 3 the focus is on reducing the number of required utility HEXs. The twostage HPB option 7 uses the lower $\Delta \mathrm{T}_{\text {lift }}$ of the respective stages and thereby achieves efficiency advantages compared to the single-stage option 5 . The implementation decision considering all these motives can be a compromise between the level of investment costs and savings in operating costs. Against this background, HPB option 4 may be the best compromise between the number of additional HEXs and the efficiency of the HP.

This is also confirmed by Figure 15, which shows the technical HP potential from the minimum value to the maximum value. The economic potential ranges from minimum to break-even, marked by the triangle. Since the minimum HPB and break-even HPB options are expressed in all cases by $\Delta \mathrm{T}_{\text {lift,min }}$ and $\Delta \mathrm{T}_{\text {lift,break-even, }}$ they do not differ in their efficiency. With the configuration 4 HEX even the economic coverage rate of the GCC can be reached. It is also interesting to see with which efficiency the heating demand can be completely covered. There, an improvement in efficiency with increasing retrofit level ( 2 HEX to $4 \mathrm{HEX)} \mathrm{can} \mathrm{be} \mathrm{observed,} \mathrm{which} \mathrm{ultimately} \mathrm{even} \mathrm{approximates} \mathrm{the} \mathrm{efficiency} \mathrm{of}$ the GCC-based potential through the possibility of a two-stage integration.

Conventional methods identify integration points under the assumption of a constant Second law efficiency using the COP curve [11]. In contrast, the targeting method described in Section 3.1 is based on the COP regression models of market-available HPs presented in Section 2. Consequently, the selection of a suitable HP is made according to the efficiency criterion and range of validity of market-available HP on the one hand and the process requirements visualised by the GCC/METD on the other. Since the presented cost parity curves only depend on the temperature lift $\Delta \mathrm{T}_{\text {lift }}$, the assumption of constant sink tem- 
perature $T_{h, o u t}$ and economic boundary conditions as well as the statistical uncertainty of the COP modelling slightly falsifies the critical temperature lift as target value. The novel targeting method using METD also meets the requirements of Fu and Gundersen [16] and Gai et al. [19] for realistic modelling of the temperature change on the process sink side. The conventional approach according to Stampfli et al. [11] used a storage-based HRL (cf. Figure $4 b$ ), which reduces the COP on the heat source and sink side due to the additional HEX temperature difference. Further efficiency potential can be tapped by directly matching continuous streams with the condenser and evaporator of the HP without HRL.
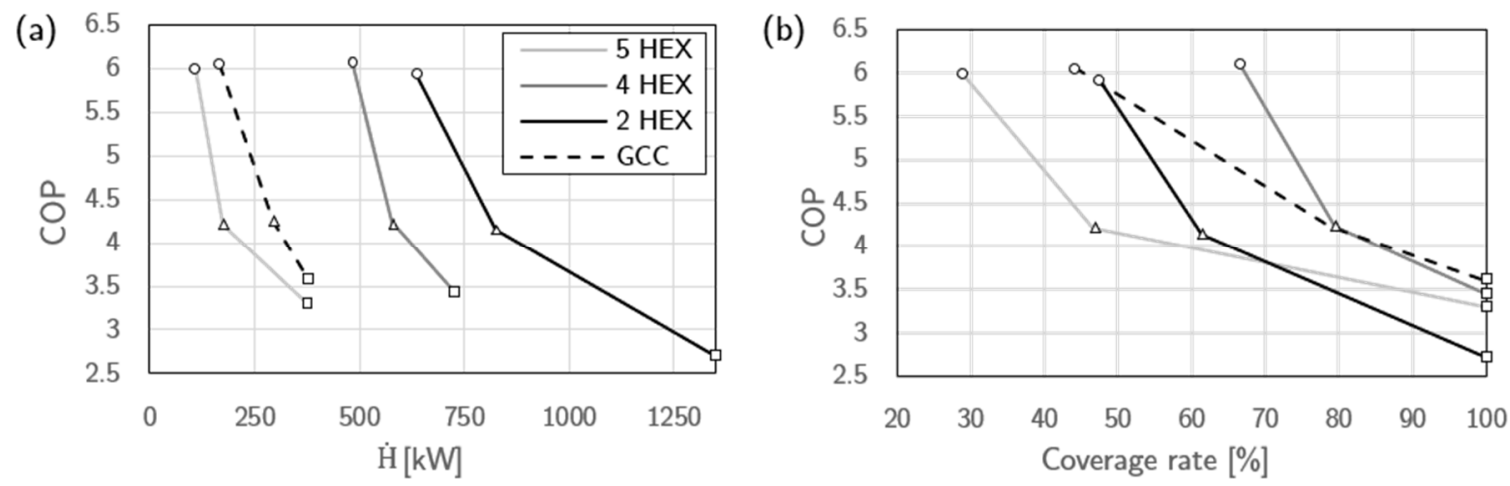

Figure 15. Targeting of technical (minimum: circle marker; maximum: square marker) and economical (triangle marker) HP potential regarding absolute (a) and relative (b) coverage of the heating demand.

\section{Conclusions}

The Heat Pump Bridge Analysis (HPBA) widens the application of Bridge Analysis and allows the exploitation of heat recovery potential by identifying retrofit bridges via direct heat exchange and the efficient integration of Heat Pumps (HPs). The targeting of different stream-specific "Heat Pump Bridge" options incorporates the use of the Coefficient of Performance (COP) curve for different market-available heat pumps and reference variables to maximise efficiency or identify economically reasonable integration points. The step-by-step modification of the Heat Exchanger Network (HEN) by iterative application of the method allows input from an engineer into the procedure to consider specific technical and economic requirements. A prerequisite for an efficient HEN and HP synthesis is the elimination of cross-Pinch violations and the alignment of heat exchangers to minimum approach temperatures by shifting duties and re-connecting of heat exchangers, which are well-known principles. The method in this paper follows these principles and enables specific identification of streams where to retrofit a HP. The matching of the capabilities of market-available HPs with the stream-specific process requirements opens up further efficiency potential and avoids incorrect sizing compared to the inaccurate approach based on a constant Second Law efficiency.

For processes with more volatile demand behaviour, the influence on the robustness of the design variables for the HP and the thermal energy storage must be statistically quantified. To this end, the use of multiple, probabilistic time series through Monte Carlo simulation is suitable. An important limitation of the method is its application to largescale problems, as opposed to a four-stream-example. For larger problems, the graphical and intuitive identification of retrofit and HP bridges becomes more difficult. As a result, future work will look to automate HPBA including the economic evaluation of HP and HEN retrofits. In addition, the database for efficiency modelling of available heat pumps should be constantly updated and supplemented by prototypes of multi-stage or multitemperature heat pumps to increase the contribution of HP to the decarbonization of the industrial heat demand also in the temperature range $>160^{\circ} \mathrm{C}$. 
Author Contributions: Conceptualization, F.S. and T.G.W.; data curation, F.S.; formal analysis, F.S. and H.W.; investigation, F.S. and H.W.; methodology, F.S. and H.W.; software, H.W.; supervision, T.G.W. and J.H.; validation, F.S. and H.W.; visualization, F.S. and H.W.; writing-original draft, F.S.; writing-review and editing, T.G.W., M.J.A. and M.R.W.W. All authors have read and agreed to the published version of the manuscript.

Funding: This research received no external funding.

Institutional Review Board Statement: Not applicable.

Informed Consent Statement: Not applicable.

Data Availability Statement: The data presented in this study are available in Jesper, M.; Schlosser, F.; Pag, F.; Schmitt, B.; Walmsley, T.G.; Vajen, K. Large-scale heat pumps: Uptake and performance modelling of market-available devices. Renew. Sustain. Energy Rev. 2020, 137, 110646, doi:10.1016/j.rser.2020.110646. and Schlosser, F.; Jesper, M.; Vogelsang, J.; Walmsley, T.G.; Arpagaus, C.; Hesselbach, J. Large-scale heat pumps: Applications, performance, economic feasibility and industrial integration. Renew. Sustain. Energy Rev. 2020, 133, 110219, doi:10.1016/j.rser.2020.110219.

Acknowledgments: The authors would like to thank all heat pump manufacturers and members of the Association of German Engineers guideline 4646 for contributing to this work by providing data and additional information presented in Section 2 and Appendix A.

Conflicts of Interest: The authors declare no conflict of interest.

\section{Nomenclature}

$\begin{array}{ll}\text { ACC } & \text { Advanced Composite Curves (ACC) } \\ \text { BA } & \text { Bridge Analysis } \\ \text { c } & \text { cold, specific heat capacity } \\ \text { C } & \text { cooling } \\ \text { CC } & \text { Composite Curves } \\ \text { COP } & \text { Coefficient of Performance } \\ \text { CP } & \text { heat capacity flow rate } \\ \text { CU } & \text { cold utility } \\ \Delta & \text { difference } \\ \text { el } & \text { electricity } \\ \text { ETD } & \text { Energy Transfer Diagram } \\ \text { Evap } & \text { evaporator } \\ \text { GCC } & \text { Grand Composite Curve } \\ \text { GHGE } & \text { greenhouse gas emissions } \\ \eta & \text { Wirkungsgrad } \\ \text { h } & \text { hot, high } \\ \text { H } & \text { heating } \\ \text { H } & \text { enthalpy flow rate } \\ \text { HEN } & \text { heat exchanger networks } \\ \text { HEX } & \text { heat exchanger } \\ \text { HFC } & \text { hydrofluorocarbons } \\ \text { HP } & \text { heat pump } \\ \text { HPBA } & \text { Heat Pump Bridge Analysis } \\ \text { HRL } & \text { heat recovery loop } \\ \text { HSDT } & \text { Heat Surplus \& Deficit Table } \\ \text { HU } & \text { hot utility } \\ \text { in } & \text { inlet } \\ \text { l } & \text { low } \\ \text { MET } & \text { minimum energy targets } \\ \text { METD } & \text { Modified Energy Transfer Diagram } \\ \text { ng } & \text { natural gas } \\ \text { p } & \text { isobaric } \\ \text { PTA } & \text { Problem Table Algorithm } \\ \text { Q } & \text { thermal capacity } \\ \text { SRTGD } & \text { Shifted Retrofit Thermodynamic Grid Diagram } \\ \text { STEP } & \text { Stream Temperature versus Enthalpy Plot } \\ \text { T } & \text { shifted temperature } \\ & \end{array}$




$\begin{array}{ll}\text { Cond } & \text { condenser } \\ \text { TDF } & \text { temperature driving force } \\ \text { out } & \text { outlet } \\ * & \text { shifted }\end{array}$

\section{Appendix A. Economic Feasibility}

Table A1. Selected nomogram parameters [3].

\begin{tabular}{|c|c|c|c|}
\hline Parameter & HP & SGB & Reference \\
\hline $\begin{array}{l}C_{I} \text { (incl. integration; } \\
\text { without planning) }\end{array}$ & $\begin{array}{l}464 € / \mathrm{kW}_{\text {th }} \\
(300 \mathrm{~kW})\end{array}$ & - & [3] \\
\hline Sink temperature $T_{h, \text { out }}$ & \multicolumn{2}{|r|}{$120^{\circ} \mathrm{C}$} & [3] \\
\hline Reference price $c_{n g}$ & $\mathrm{c}_{\mathrm{el}}=\mathrm{c}_{\mathrm{el}} / \mathrm{c}_{\mathrm{ng}} * \mathrm{c}_{\mathrm{ng}}$ & $0.0315 € / \mathrm{kWh}$ & {$[40]$} \\
\hline Operating hours $\mathrm{t}_{\mathrm{oh}}$ & & $6000 \mathrm{~h} / \mathrm{y}$ & \\
\hline Interest-rate factor $\mathrm{q}$ & & 1.12 & \\
\hline Depreciation period N & & $20 \mathrm{y}$ & [41] \\
\hline Maintenance factor $\mathrm{f}_{\mathrm{m}}$ & $2.5 \%$ & $3.5 \%\left(C_{\mathrm{I}, \mathrm{SGB}}=131 € / \mathrm{kW}_{\text {th }}\right.$ & [41] \\
\hline Full load efficiency $\eta_{100}$ & $\mathrm{COP}_{\mathrm{i}}\left(\Delta \mathrm{T}_{\text {lift }}\right)$ & $0.87(300 \mathrm{~kW})$ & Table A2, [41] \\
\hline
\end{tabular}

Table A2. Recommended fitting parameters of the Equation (2) representing COP $\left(\Delta \mathrm{T}_{\text {lift }}, \mathrm{T}_{\mathrm{h} \text {,out }}\right)$ for SHP, water/water-VHTHP, SHP with R717, water/steam-VHTHP and COP $\left(\Delta \mathrm{T}_{\text {lift,m }}, \mathrm{T}_{\mathrm{h}, \mathrm{m}}\right)$ for $\mathrm{CO}_{2}-\mathrm{HP}$ based on Equation (3) [3].

\begin{tabular}{|c|c|c|c|}
\hline & Fitting Parameter & $\sigma$ & $\mathbf{R}^{2}$ \\
\hline $\begin{array}{l}\text { SHP } \\
\text { Range of validity }\end{array}$ & $\begin{array}{c}\mathrm{a}=1.4480 \cdot 10^{12}, \mathrm{~b}=88.730, \mathrm{c}=-4.9460, \mathrm{~d}=0.0000 \\
-10^{\circ} \mathrm{C} \leq \mathrm{T}_{1, \text { in }}<60^{\circ} \mathrm{C} \\
25^{\circ} \mathrm{C} \leq \mathrm{T}_{\mathrm{h}, \text { out }}<100^{\circ} \mathrm{C} \\
10 \mathrm{~K} \leq \Delta \mathrm{T}_{\text {lift }} \leq 78 \mathrm{~K}\end{array}$ & 0.28 & 0.96 \\
\hline $\begin{array}{c}\text { water/water-VHTHP } \\
\text { Range of validity }\end{array}$ & $\begin{array}{c}\mathrm{a}=1.9118, \mathrm{~b}=0.044189, \mathrm{c}=-0.89094, \mathrm{~d}=0.67895 \\
25^{\circ} \mathrm{C} \leq \mathrm{T}_{1, \text { in }} \leq 110^{\circ} \mathrm{C} \\
80^{\circ} \mathrm{C} \leq \mathrm{T}_{\mathrm{h}, \text { out }} \leq 160^{\circ} \mathrm{C} \\
25 \mathrm{~K} \leq \Delta \mathrm{T}_{\text {lift }} \leq 95 \mathrm{~K}\end{array}$ & 0.19 & 0.95 \\
\hline $\begin{array}{l}\text { SHP with R717 } \\
\text { Range of validity }\end{array}$ & $\begin{aligned} & \mathrm{a}=40.789, \mathrm{~b}=1.0305, \mathrm{c}=-1.0489, \mathrm{~d}=0.29998 \\
& 0{ }^{\circ} \mathrm{C} \leq \mathrm{T}_{1, \text { in }} \leq 40^{\circ} \mathrm{C} \\
& 70{ }^{\circ} \mathrm{C} \leq \mathrm{T}_{\mathrm{h}, \text { out }} \leq 85^{\circ} \mathrm{C} \\
& 30 \mathrm{~K} \leq \Delta \mathrm{T}_{\text {lift }} \leq 75 \mathrm{~K}\end{aligned}$ & 0.42 & 0.87 \\
\hline water/steam-VHTHP & $\begin{array}{c}\mathrm{a}=8.8980, \mathrm{~b}=0.042214, \mathrm{c}=-0.52137, \mathrm{~d}=0.16395 \\
55^{\circ} \mathrm{C} \leq \mathrm{T}_{1, \text { in }} \leq 110^{\circ} \mathrm{C} \\
\mathrm{T}_{\mathrm{h}, \text { in }}=95^{\circ} \mathrm{C} \\
110^{\circ} \mathrm{C} \leq \mathrm{T}_{\mathrm{h}, \text { out }} \leq 160^{\circ} \mathrm{C} \\
25 \mathrm{~K} \leq \Delta \mathrm{T}_{\text {lift }} \leq 70 \mathrm{~K}\end{array}$ & 0.20 & 0.77 \\
\hline Range of validity & $\begin{array}{c}\mathrm{a}=1261.2, \mathrm{~b}=17.627, \mathrm{c}=-1.3974, \mathrm{~d}=0,0000 \\
\quad-4{ }^{\circ} \mathrm{C} \leq \mathrm{T}_{\mathrm{l}, \mathrm{in}} \leq 35^{\circ} \mathrm{C} \\
25{ }^{\circ} \mathrm{C} \leq \mathrm{T}_{\mathrm{h}, \text { out }} \leq 90{ }^{\circ} \mathrm{C} \quad 291 \mathrm{~K} \leq \mathrm{T}_{\mathrm{h}, \mathrm{m}} \leq 343 \mathrm{~K} \\
5 \mathrm{~K} \leq \mathrm{T}_{\mathrm{h}, \text { out }}-\mathrm{T}_{\mathrm{h}, \text { in }} \leq 80 \mathrm{~K} \\
7 \mathrm{~K} \leq \Delta \mathrm{T}_{\text {lift }} \leq 94 \mathrm{~K} \quad 0 \mathrm{~K}<\Delta \mathrm{T}_{\text {lift, }} \leq 74 \mathrm{~K}\end{array}$ & 0.47 & 0.90 \\
\hline
\end{tabular}

\section{References}

1. Linnhoff, B.; Flower, J.R. Synthesis of heat exchanger networks: I. Systematic generation of energy optimal networks. AIChE J. 1978, 24, 633-642. [CrossRef]

2. Philipp, M.; Schumm, G.; Schlosser, F.; Peesel, R.-H.; Holzhammer, U. Basic issues of waste heat recovery: Exploiting efficiency improvement potentials in industry through waste heat utilisation. BWK Energ. Fachmag. 2016, 69, 36-39. (In German)

3. Schlosser, F.; Jesper, M.; Vogelsang, J.; Walmsley, T.G.; Arpagaus, C.; Hesselbach, J. Large-scale heat pumps: Applications, performance, economic feasibility and industrial integration. Renew. Sustain. Energy Rev. 2020, 133, 110219. [CrossRef]

4. Schlosser, F.; Seevers, J.-P.; Peesel, R.-H.; Walmsley, T.G. System efficient integration of standby control and heat pump storage systems in manufacturing processes. Energy 2019, 181, 395-406. [CrossRef] 
5. Hoffmann, C. Energy Transition Barometer; Fraunhofer Institute for Energy Economics and Energy System Technology (IEE): Kassel, Germany, 2018. (In German)

6. Wolf, S. Integration of Heat Pumps in Industrial Production Systems: Potentials and Instruments for Potential Exploitation. Ph.D. Thesis, University of Stuttgart, Stuttgart, Germany, 2017. (In German).

7. Arpagaus, C.; Bless, F.; Uhlmann, M.; Schiffmann, J.; Bertsch, S. High temperature heat pumps: Market overview, state of the art, research status, refrigerants, and application potentials. Energy 2018, 152, 985-1010. [CrossRef]

8. Wietschel, M. Integration of Renewable Energies by Sector Coupling: Analysis of Technical Sector Coupling Options; Final report; German Environment Agency (UBA): Dessau-Roßlau, Germany, 2019. (In German)

9. Townsend, D.W.; Linnhoff, B. Heat and power networks in process design. Part I: Criteria for placement of heat engines and heat pumps in process networks. AIChE J. 1983, 29, 742-748. [CrossRef]

10. Wallin, E.; Franck, P.Å.; Berntsson, T. Heat pumps in industrial processes-An optimization methodology. Heat Recovery Syst. CHP 1990, 10, 437-446. [CrossRef]

11. Stampfli, J.A.; Atkins, M.J.; Olsen, D.G.; Walmsley, M.R.W.; Wellig, B. Practical heat pump and storage integration into non-continuous processes: A hybrid approach utilizing insight based and nonlinear programming techniques. Energy 2019, 182, 236-253. [CrossRef]

12. Stampfli, J.A.; Atkins, M.J.; Olsen, D.G.; Wellig, B.; Walmsley, M.R.W.; Neale, J.R. Industrial Heat Pump Integration in NonContinuous Processes Using Thermal Energy Storages as Utility-A Graphical Approach. Chem. Eng. Trans. 2018, 70, 901-906. [CrossRef]

13. Wang, Y.P.; Smith, R. Time Pinch Analysis. Chem. Eng. Res. Des. 1995, 73, 905-914.

14. Schlosser, F.; Arpagaus, C.; Walmsley, T.G. Heat Pump Integration by Pinch Analysis for Industrial Applications: A Review. Chem. Eng. Trans. 2019, 76, 7-12. [CrossRef]

15. Van de Bor, D.M.; Infante Ferreira, C.A. Quick selection of industrial heat pump types including the impact of thermodynamic losses. Energy 2013, 53, 312-322. [CrossRef]

16. Fu, C.; Gundersen, T. A Novel Sensible Heat Pump Scheme for Industrial Heat Recovery. Ind. Eng. Chem. Res. 2016, 55, 967-977. [CrossRef]

17. Oluleye, G.; Smith, R.; Jobson, M. Modelling and screening heat pump options for the exploitation of low grade waste heat in process sites. Appl. Energy 2016, 169, 267-286. [CrossRef]

18. Wang, M.; Deng, C.; Wang, Y.; Feng, X.; Lan, X. Process Integration and Selection of Heat Pumps in Industrial Processes. Chem. Eng. Trans. 2018, 70, 1105-1110. [CrossRef]

19. Gai, L.; Varbanov, P.S.; Walmsley, T.G.; Klemeš, J. Critical Analysis of Process Integration Options for Joule-Cycle and Conventional Heat Pumps. Energies 2020, 13, 635. [CrossRef]

20. Yang, M.; Li, T.; Feng, X.; Wang, Y. A simulation-based targeting method for heat pump placements in heat exchanger networks. Energy 2020, 203, 117907. [CrossRef]

21. Lai, Y.Q.; Manan, Z.A.; Wan Alwi, S.R. Simultaneous diagnosis and retrofit of heat exchanger network via individual process stream mapping. Energy 2018, 155, 1113-1128. [CrossRef]

22. Akpomiemie, M.O.; Smith, R. Retrofit of heat exchanger networks without topology modifications and additional heat transfer area. Appl. Energy 2015, 159, 381-390. [CrossRef]

23. Nordman, R.; Berntsson, T. Use of advanced composite curves for assessing cost-effective HEN retrofit I: Theory and concepts. Appl. Therm. Eng. 2009, 29, 275-281. [CrossRef]

24. Lai, Y.Q.; Manan, Z.A.; Alwi, S.R.W. Heat Exchanger Network Retrofit Using Individual Stream Temperature vs Enthalpy Plot. Chem. Eng. Trans. 2017, 61, 1651-1656.

25. Kamel, D.A.; Gadalla, M.A.; Abdelaziz, O.Y.; Labib, M.A.; Ashour, F.H. Temperature driving force (TDF) curves for heat exchanger network retrofit-A case study and implications. Energy 2017, 123, 283-295. [CrossRef]

26. Yong, J.Y.; Varbanov, P.S.; Klemeš, J. Heat exchanger network retrofit supported by extended Grid Diagram and heat path development. Appl. Therm. Eng. 2015, 89, 1033-1045. [CrossRef]

27. Bonhivers, J.-C.; Korbel, M.; Sorin, M.; Savulescu, L.; Stuart, P.R. Energy transfer diagram for improving integration of industrial systems. Appl. Therm. Eng. 2014, 63, 468-479. [CrossRef]

28. Varbanov, P.S.; Klemeš, J. Rules for paths construction for HENs debottlenecking. Appl. Therm. Eng. 2000, 20, 1409-1420. [CrossRef]

29. Bonhivers, J.-C.; Srinivasan, B.; Stuart, P.R. New analysis method to reduce the industrial energy requirements by heat-exchanger network retrofit: Part 1-Concepts. Appl. Therm. Eng. 2017, 119, 659-669. [CrossRef]

30. Bonhivers, J.-C.; Alva-Argaez, A.; Srinivasan, B.; Stuart, P.R. New analysis method to reduce the industrial energy requirements by heat-exchanger network retrofit: Part 2-Stepwise and graphical approach. Appl. Therm. Eng. 2017, 119, 670-686. [CrossRef]

31. Walmsley, M.R.W.; Lai, Y.Q.; Walmsley, T.G.; Atkins, M.J. A Modified Energy Transfer Diagram forHeat Exchanger Network Retrofit Bridge Analysis. Chem. Eng. Trans. 2017, 907-912.

32. Lal, N.S.; Walmsley, T.G.; Walmsley, M.R.W.; Atkins, M.J.; Neale, J.R. A novel Heat Exchanger Network Bridge Retrofit method using the Modified Energy Transfer Diagram. Energy 2018, 155, 190-204. [CrossRef]

33. Walmsley, T.G.; Lal, N.S.; Varbanov, P.S.; Klemeš, J. Automated retrofit targeting of heat exchanger networks. Front. Chem. Sci. Eng. 2018, 12, 630-642. [CrossRef] 
34. DIN German Institute for Standardization. Air Conditioners, Liquid Chilling Packages and Heat Pumps for Space Heating and Cooling and Process Chillers, with Electrically Driven Compressors_Part 2: Test Conditions; Beuth Verlag: Berlin, Germany, 2018. (In German)

35. Jesper, M.; Schlosser, F.; Pag, F.; Schmitt, B.; Walmsley, T.G.; Vajen, K. Large-scale heat pumps: Uptake and performance modelling of market-available devices. Renew. Sustain. Energy Rev. 2020, 137, 110646. [CrossRef]

36. Eurostat. Electricity Prices for Non-Household Consumer \& Gas Prices for Non-Household Consumer. Available online: https: / / ec.europa.eu/eurostat/web/energy/data/database (accessed on 10 December 2019).

37. Klemeš, J.; Alwi, S.R.W.; Manan, Z.A.; Varbanov, P.S. Process Integration and Intensification. Saving Energy, Water and Resources; De Gruyter: Berlin, Germany; Boston, MA, USA, 2014; ISBN 978-3-11-030685-9.

38. Becker, H. Methodology and Thermo-Economic Optimization for Integration of Industrial Heat Pumps. Ph.D. Thesis, École Polytechnique Fédérale de Lausanne, Lausanne, Switzerland, 2012.

39. Linnhoff, B.; Townsend, D.W.; Boland, D.; Hewitt, G.F.; Thomas, B.E.A.; Guy, A.R.; Marsland, R.H. User Guide on Process Integration for the Efficient Use of Energy; Pergamon Press: Oxford, UK, 1982.

40. Eurostat. Electricity Prices and Gas Prices for Non-Household Consumer. Second Half-Year 2019. 2020. Available online: https: / / ec.europa.eu/eurostat/web/energy/data/database (accessed on 12 July 2020).

41. Association of German Engineers. Economic Efficiency of Building Installations. Fundamentals and Economic Calculation; Beuth Verlag: Berlin, Germany, 2012; 91.140 .01 (2067 Part 1 \& 40). (In German) 